Supporting information

for

\title{
Highly Regio- and Chemoselective Ring Opening of Oxa-Bridged Piperidinones toward Functionalized Furanones and Piperidines
}

Sengodagounder Muthusamy, ${ }^{,}{ }^{\dagger}$ Janagiraman Krishnamurthi, $^{\dagger}$ and Eringathodi Suresh ${ }^{\ddagger}$

School of Chemistry, Bharathidasan University, Tiruchirappalli, Tamilnadu - 620024 India, and Central Salt \& Marine Chemicals Research Institute, Bhavnagar, Gujarat364002 India

muthu@bdu.ac.in

\section{List of Contents}

Spectra for the synthesized new compounds

$\begin{array}{ll}{ }^{1} \mathrm{H} \text { NMR and }{ }^{13} \mathrm{C} \text { NMR of compound } \mathbf{4 a} & \text { Page S2-S3 } \\ { }^{1} \mathrm{H} \text { NMR and }{ }^{13} \mathrm{C} \text { NMR of compound } \mathbf{4 b} & \text { Page S4-S5 } \\ { }^{1} \mathrm{H} \text { NMR and }{ }^{13} \mathrm{C} \text { NMR of compound } \mathbf{4 c} & \text { Page S6-S7 } \\ { }^{1} \mathrm{H} \text { NMR and }{ }^{13} \mathrm{C} \text { NMR of compound } \mathbf{7 a} & \text { Page S8-S9 } \\ { }^{1} \mathrm{H} \text { NMR and }{ }^{13} \mathrm{C} \text { NMR of compound } \mathbf{7 b} & \text { Page S10-S11 } \\ { }^{1} \mathrm{H} \text { NMR and }{ }^{13} \mathrm{C} \text { NMR of compound } \mathbf{7} & \text { Page S12-S13 } \\ { }^{1} \mathrm{H} \text { NMR and }{ }^{13} \mathrm{C} \text { NMR of compound } \mathbf{7 e} & \text { Page S14-S15 } \\ { }^{1} \mathrm{H} \text { NMR and }{ }^{13} \mathrm{C} \text { NMR of compound } \mathbf{7} & \text { Page S16-S17 } \\ { }^{1} \mathrm{H} \text { NMR and }{ }^{13} \mathrm{C} \text { NMR of compound } \mathbf{9 a} & \text { Page S18-S19 } \\ { }^{1} \mathrm{H} \text { NMR and }{ }^{13} \mathrm{C} \text { NMR of compound } \mathbf{9 c} & \text { Page S20-S21 } \\ { }^{1} \mathrm{H} \text { NMR and }{ }^{13} \mathrm{C} \text { NMR of compound } \mathbf{9 d} & \text { Page S22-S23 } \\ { }^{1} \mathrm{H} \text { NMR and }{ }^{13} \mathrm{C} \text { NMR of compound } \mathbf{9 g} & \text { Page S24-S25 } \\ { }^{1} \mathrm{H} \text { NMR and }{ }^{13} \mathrm{C} \text { NMR of compound } \mathbf{1 2} & \text { Page S26-S27 } \\ { }^{1} \mathrm{H} \text { NMR and }{ }^{13} \mathrm{C} \text { NMR of compound } \mathbf{1 4} & \text { Page S28-S29 } \\ { }^{1} \mathrm{H} \text { NMR and }{ }^{13} \mathrm{C} \text { NMR of compound } \mathbf{1 6} & \text { Page S30-S31 }\end{array}$




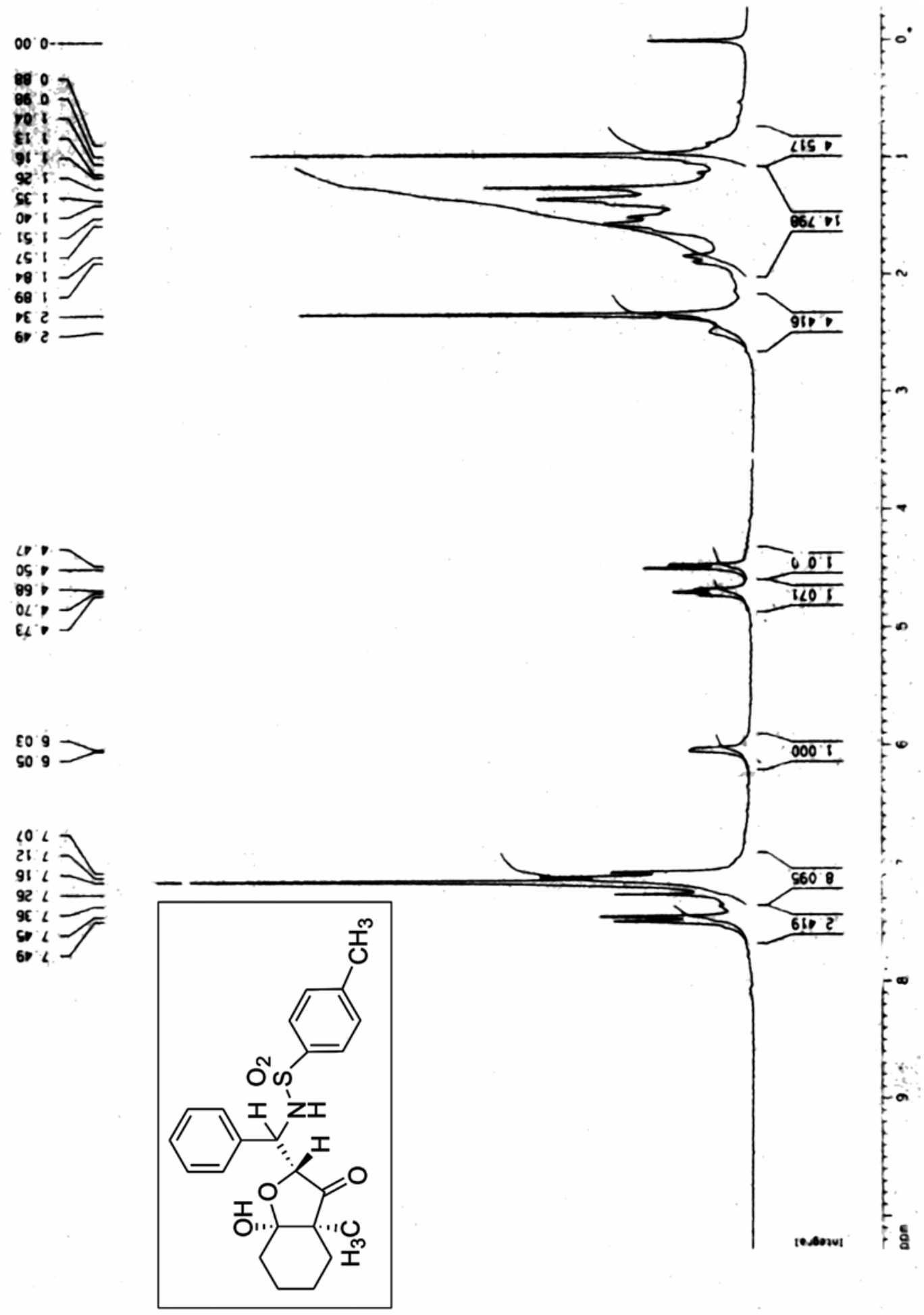




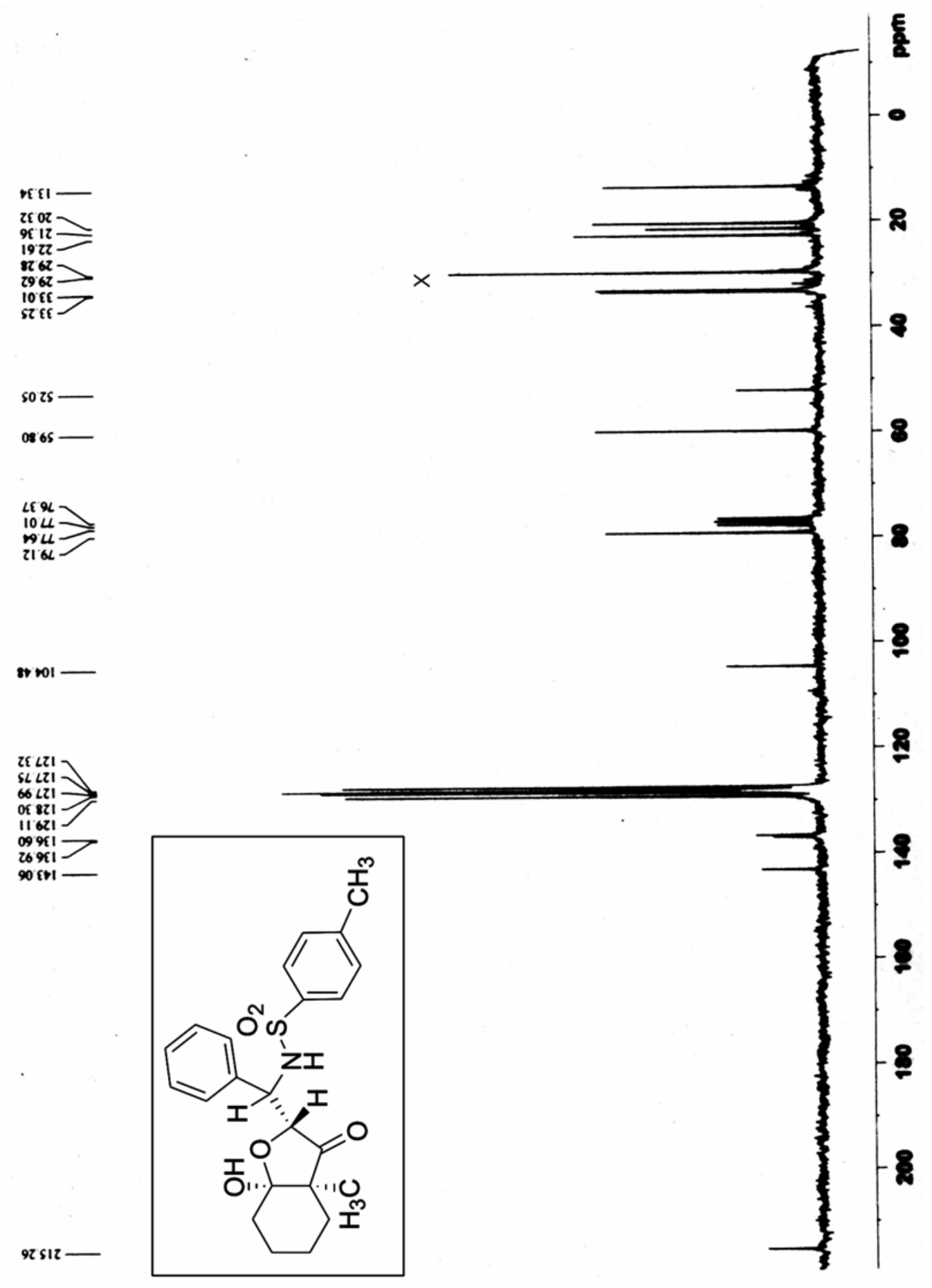




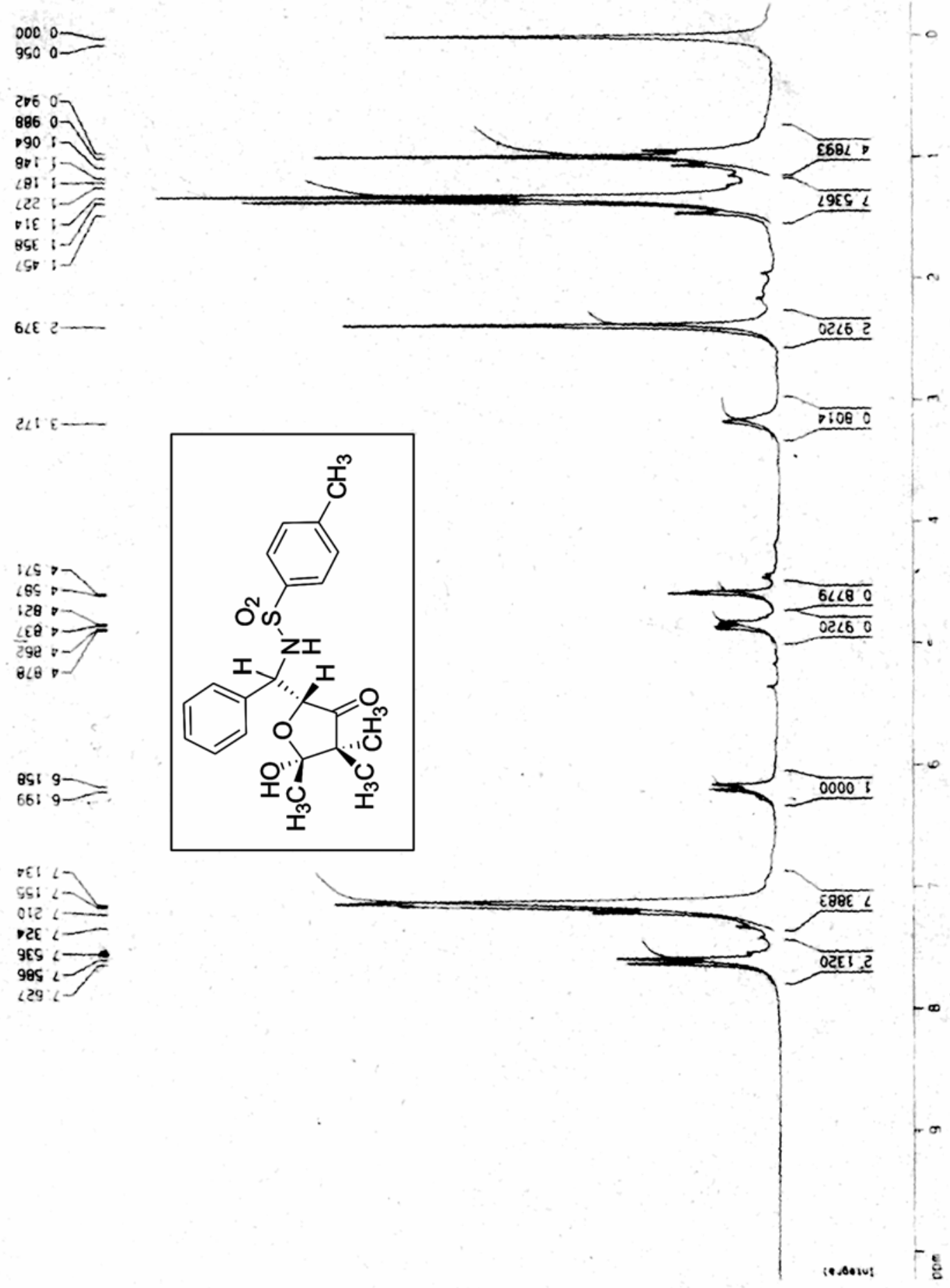



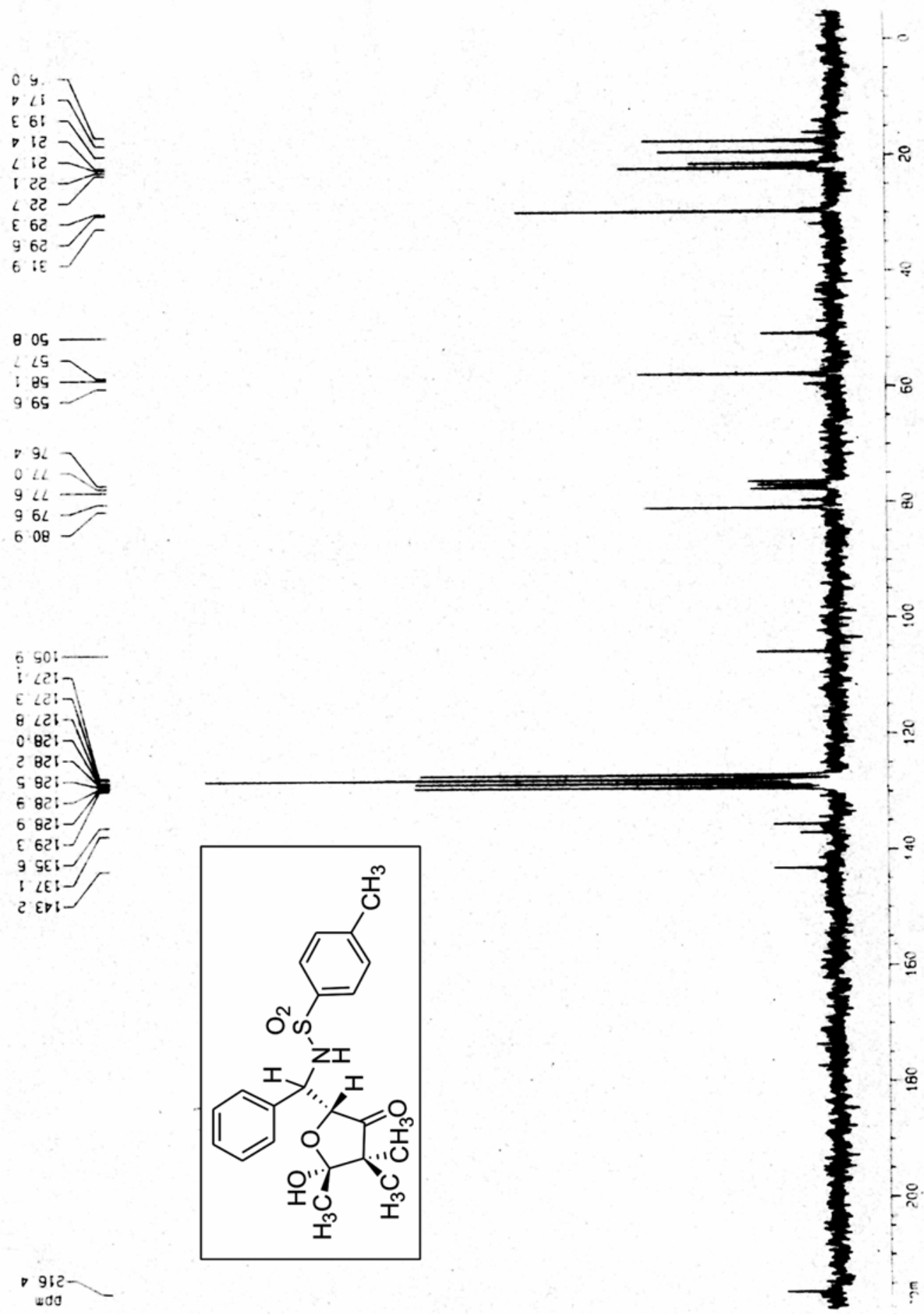


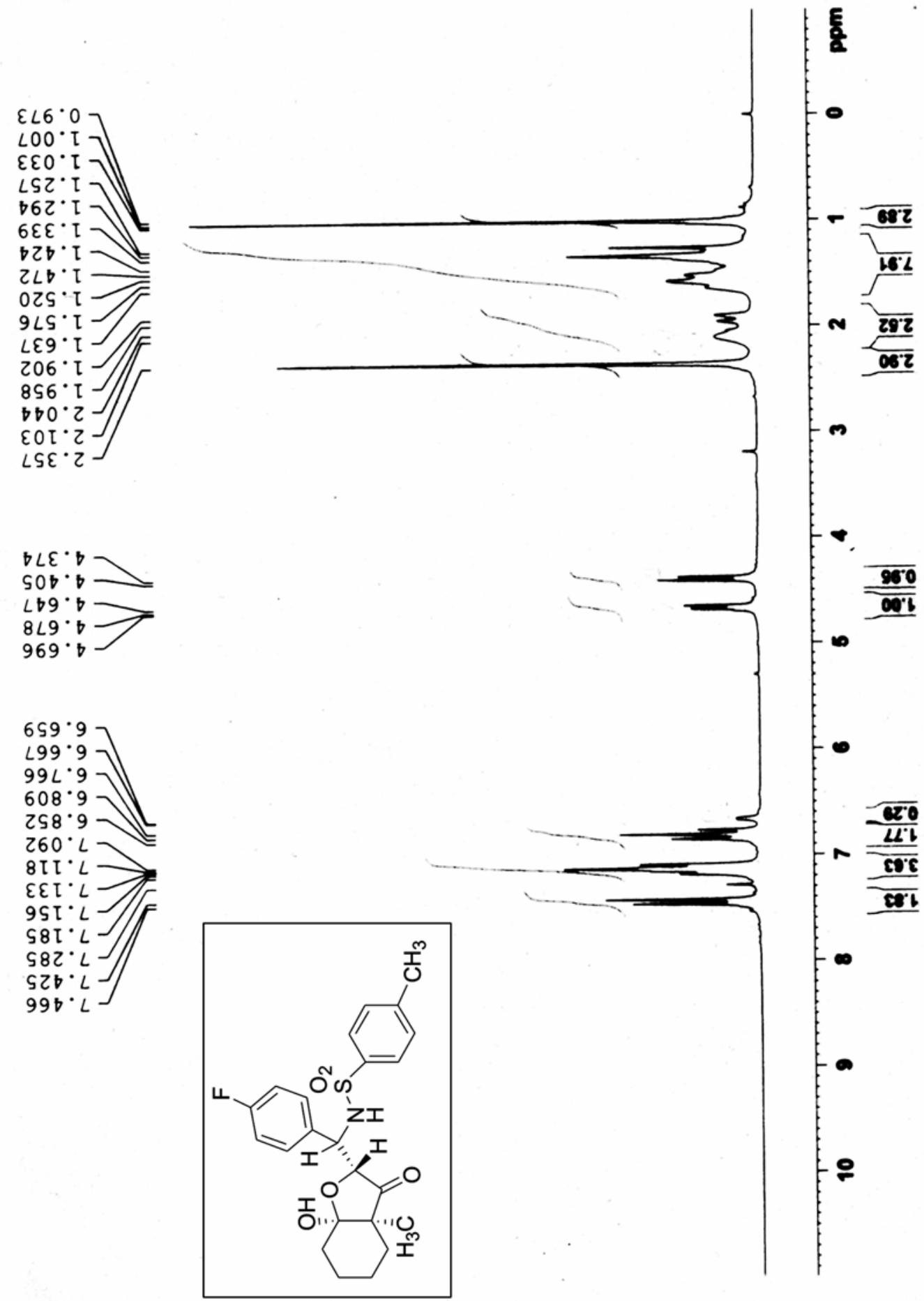




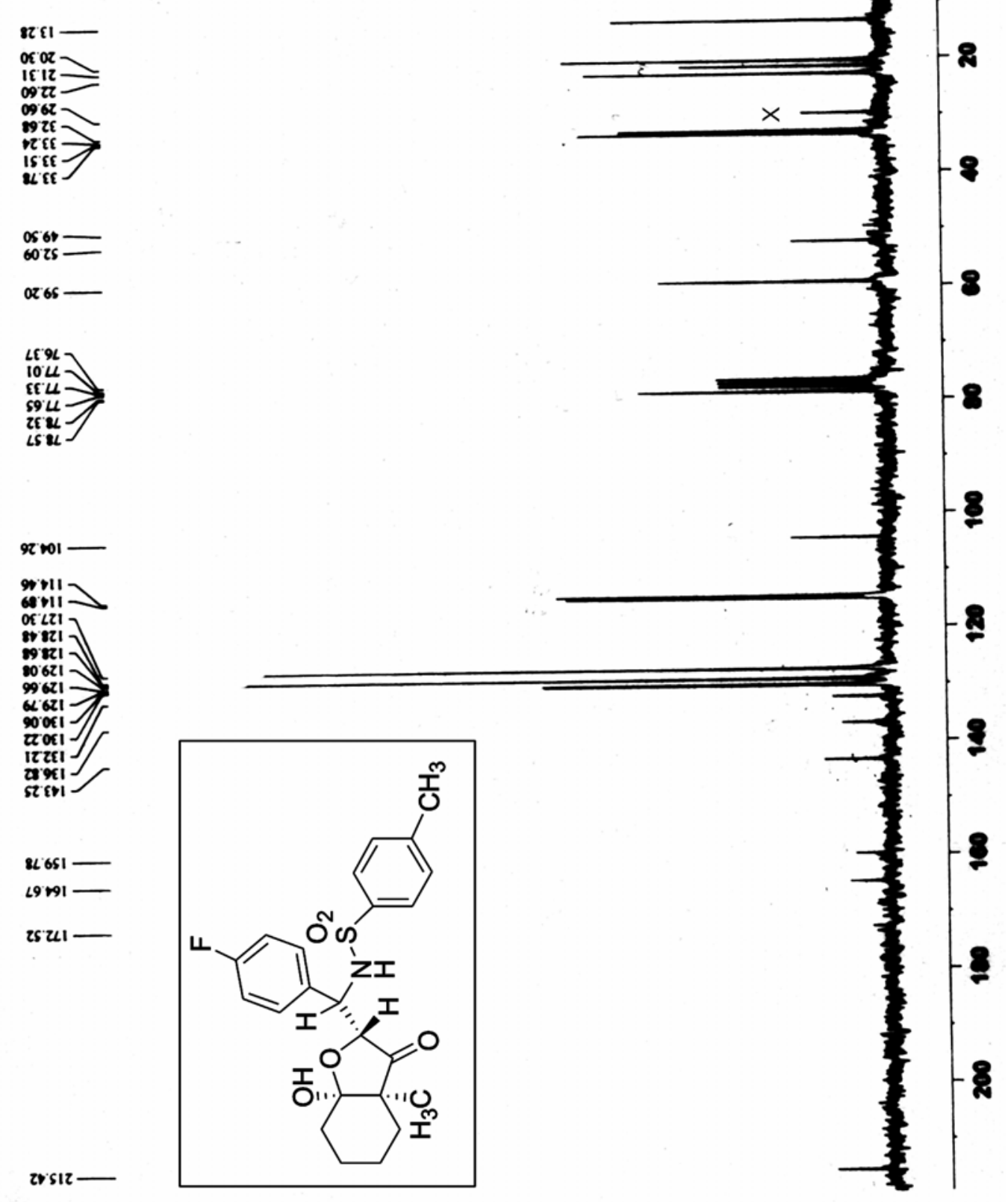




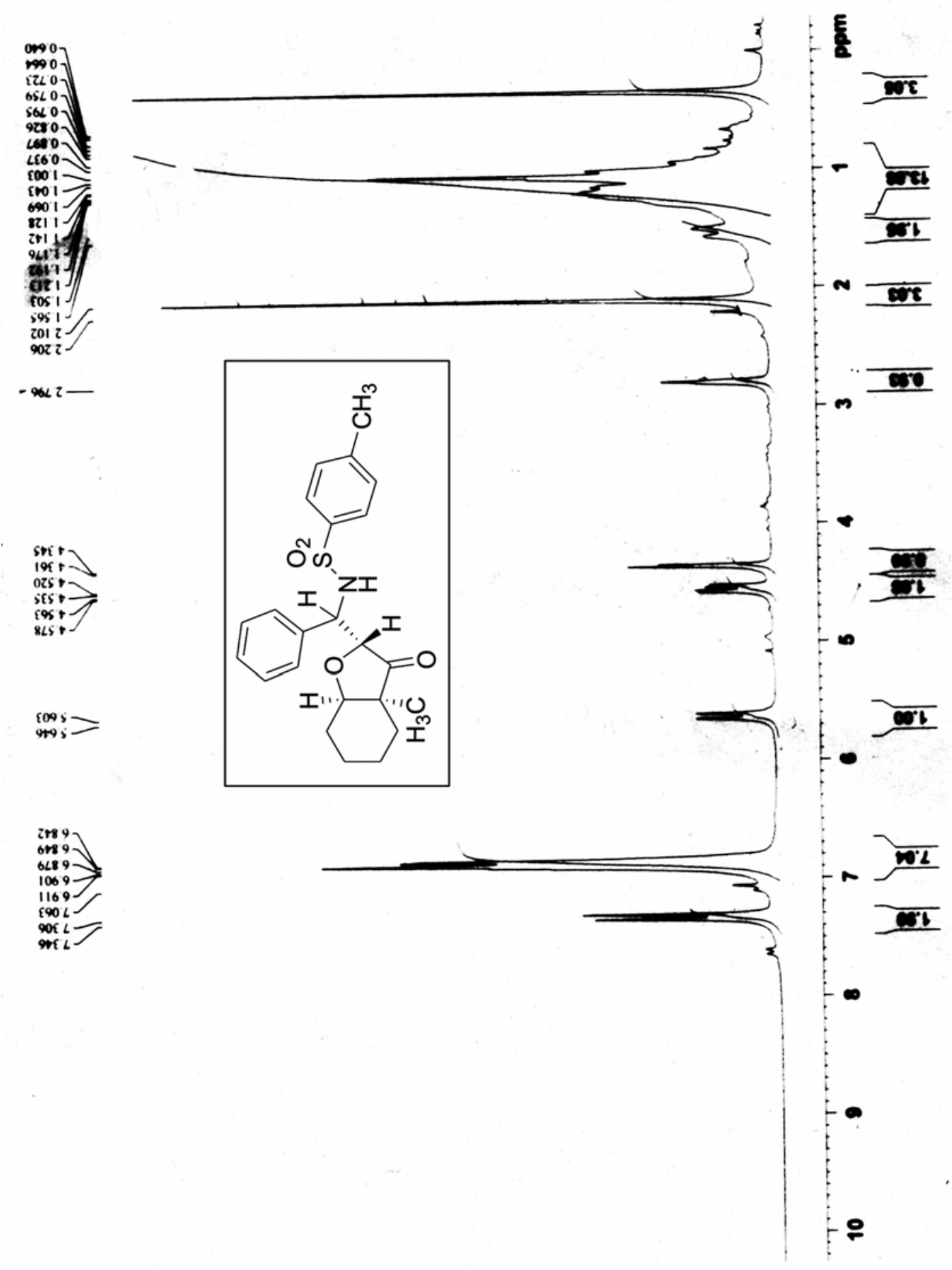




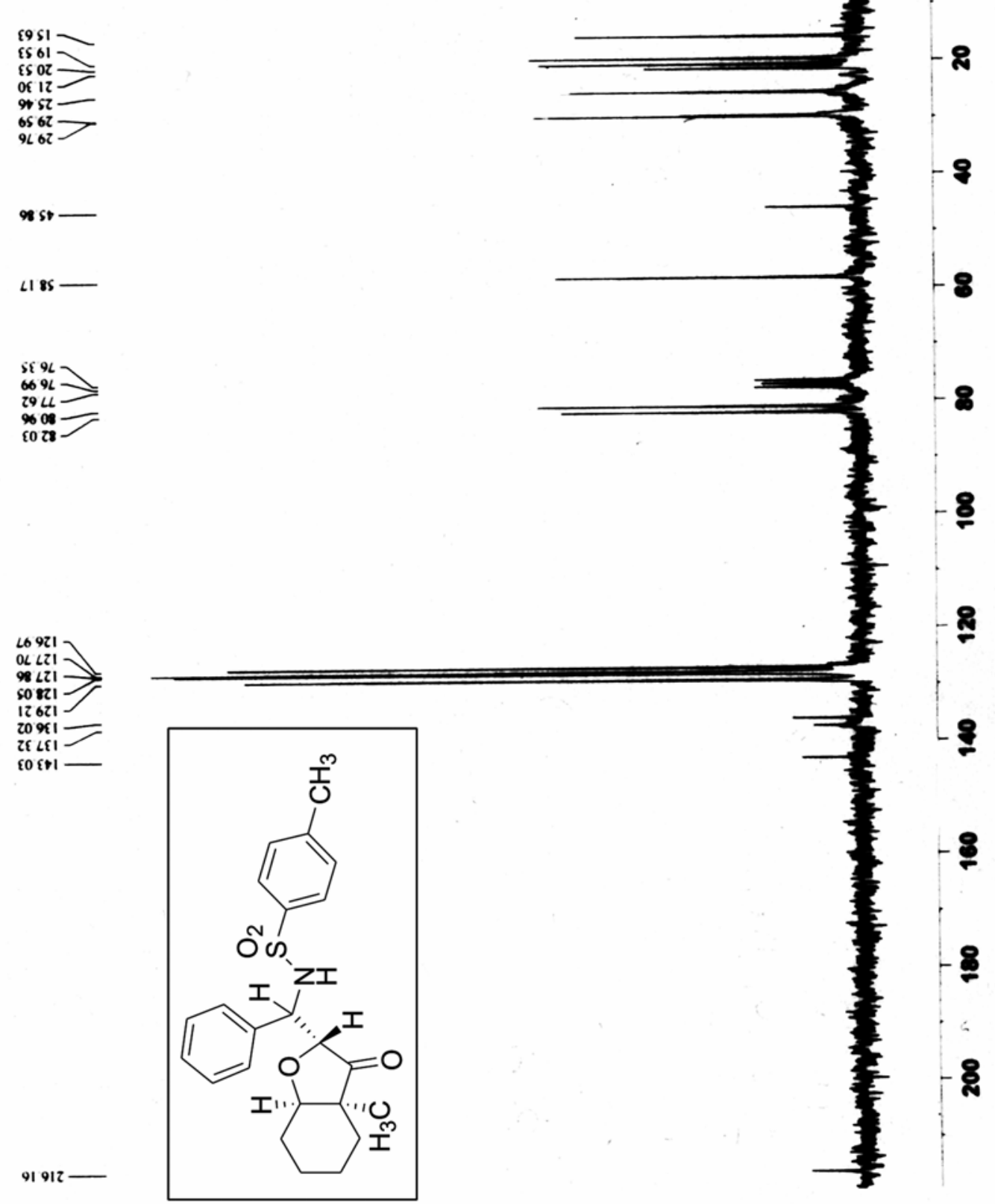




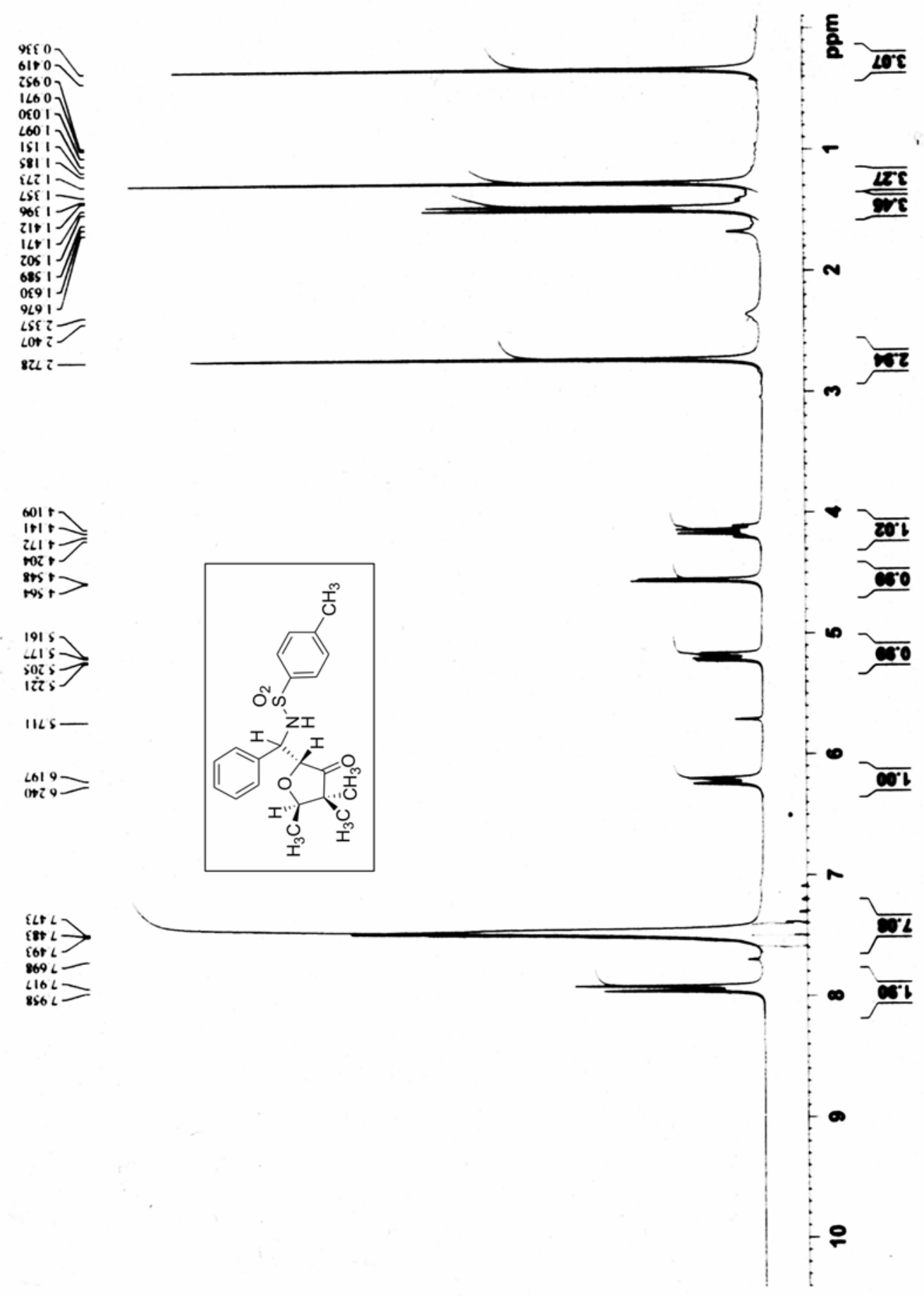



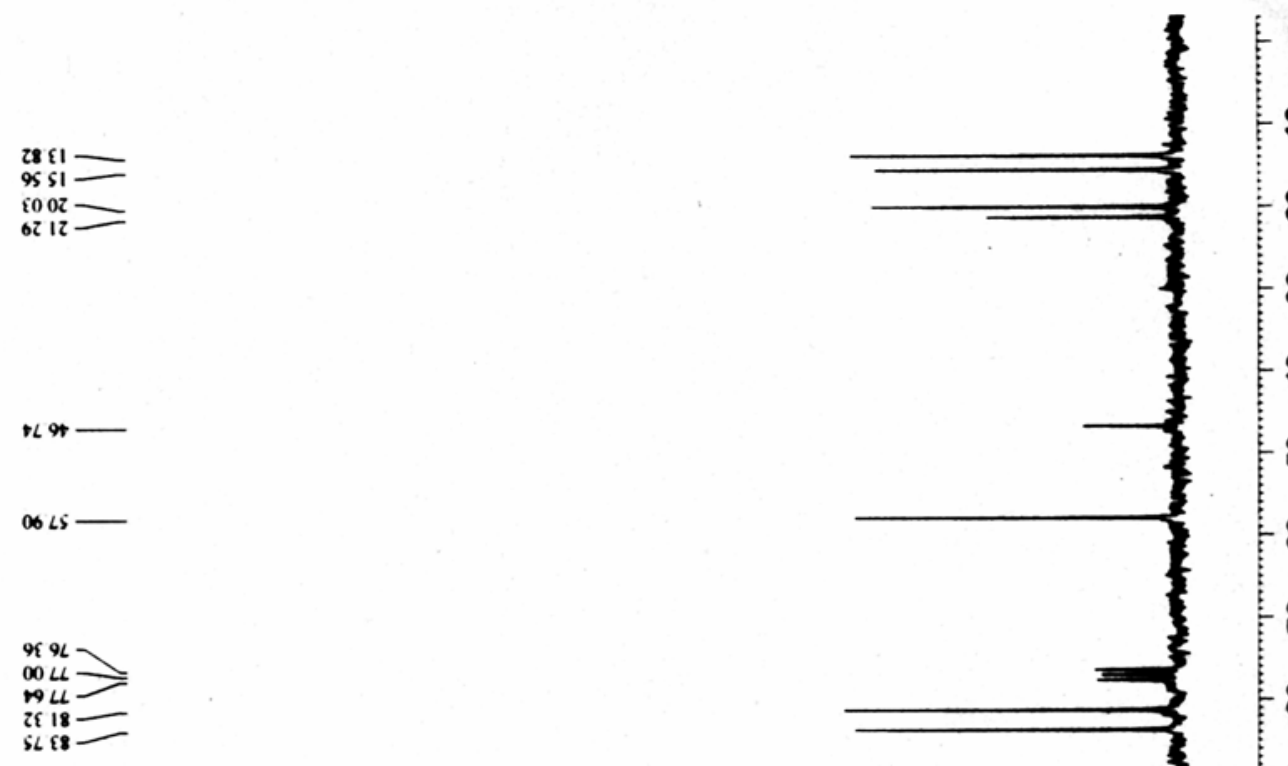

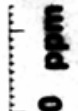

우

8

$-8$

$-8$

$-8$

8

웅

의

₹\& 18 二

9921

$\llbracket\llcorner z 1-$

\begin{tabular}{l}
$<9<21$ \\
\hline$<81$
\end{tabular}

\$1 621

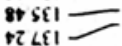

Lo $2+1$

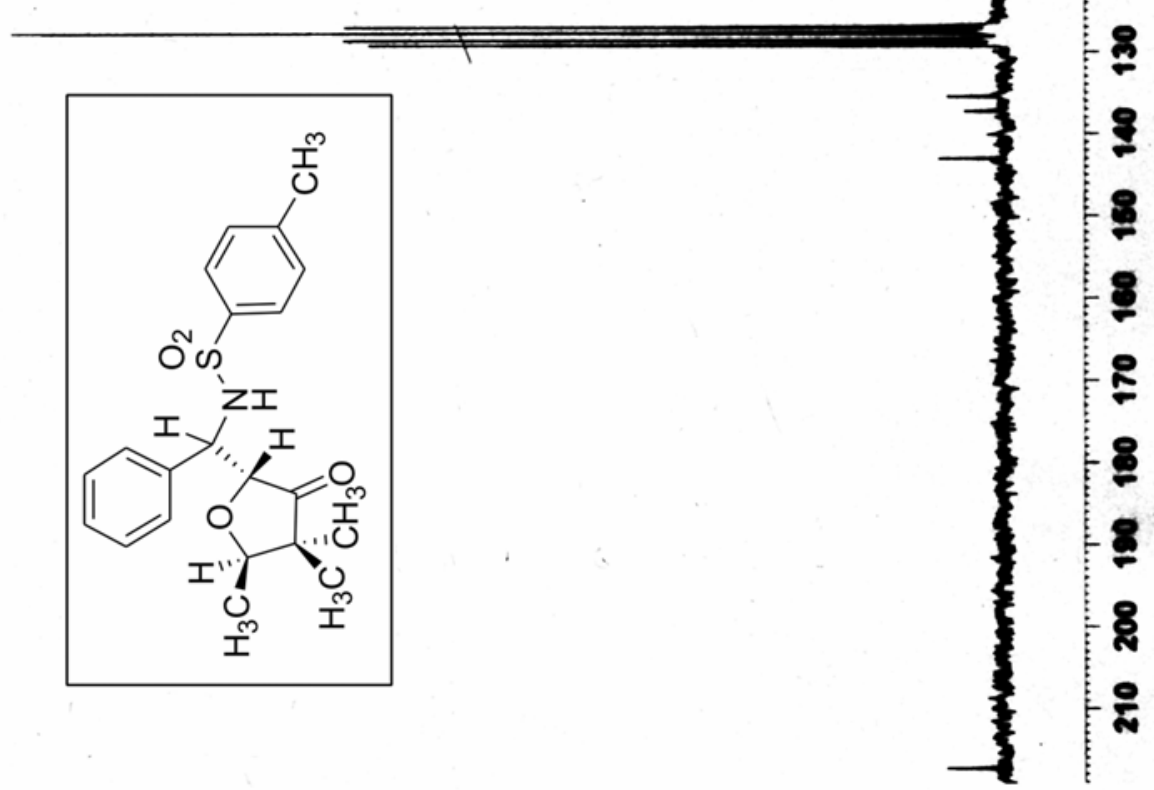

$6 z<12-$ 


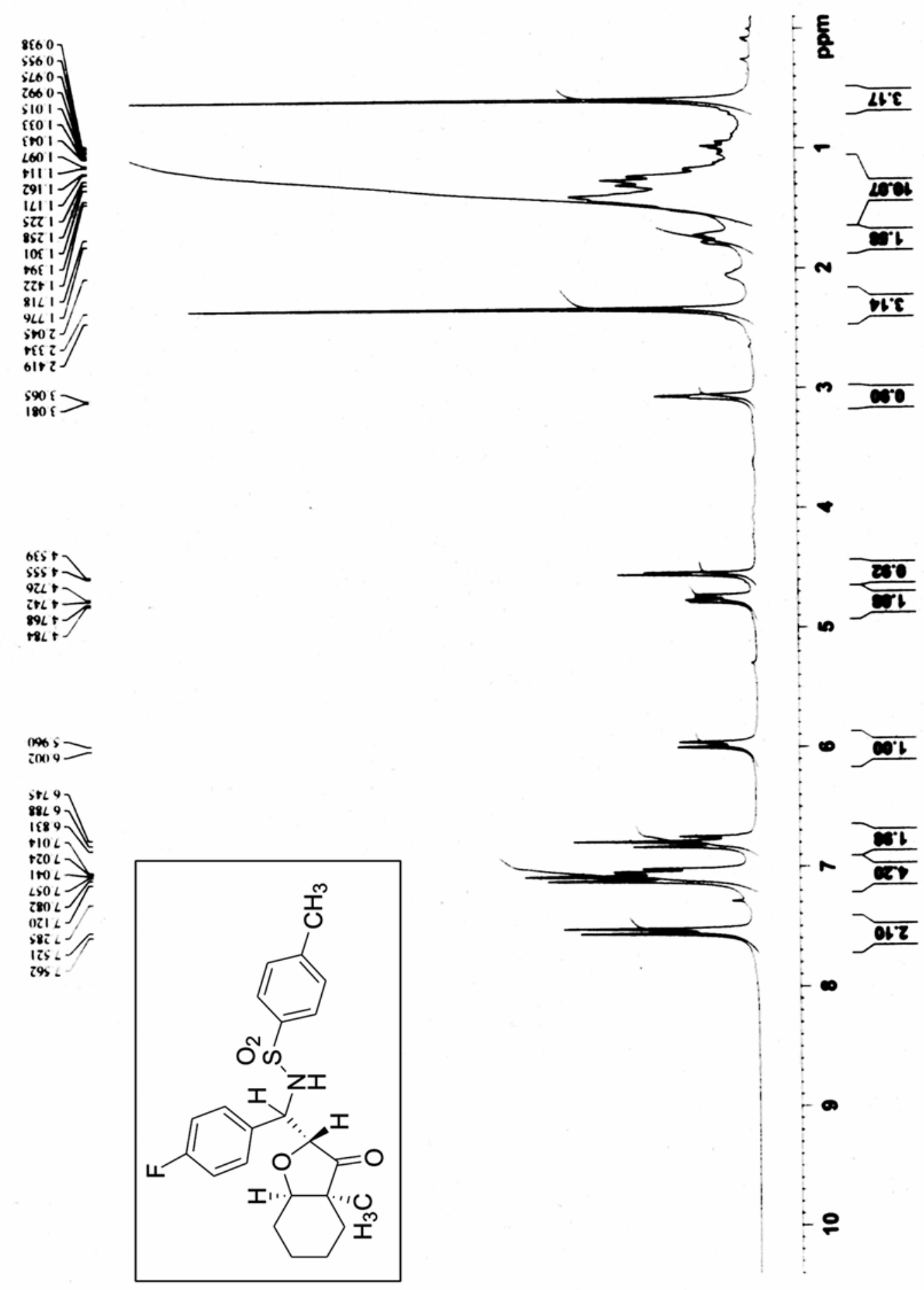




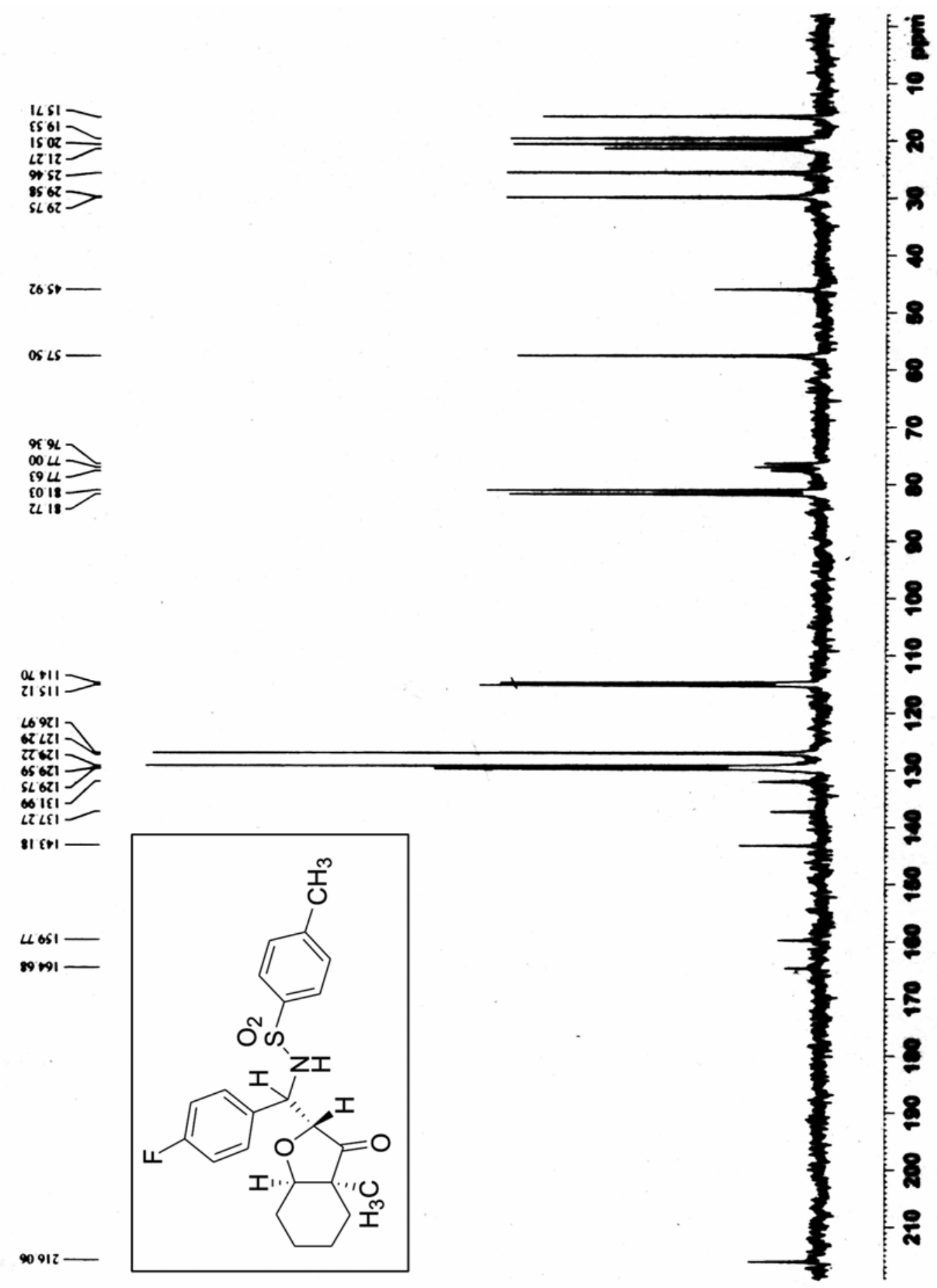




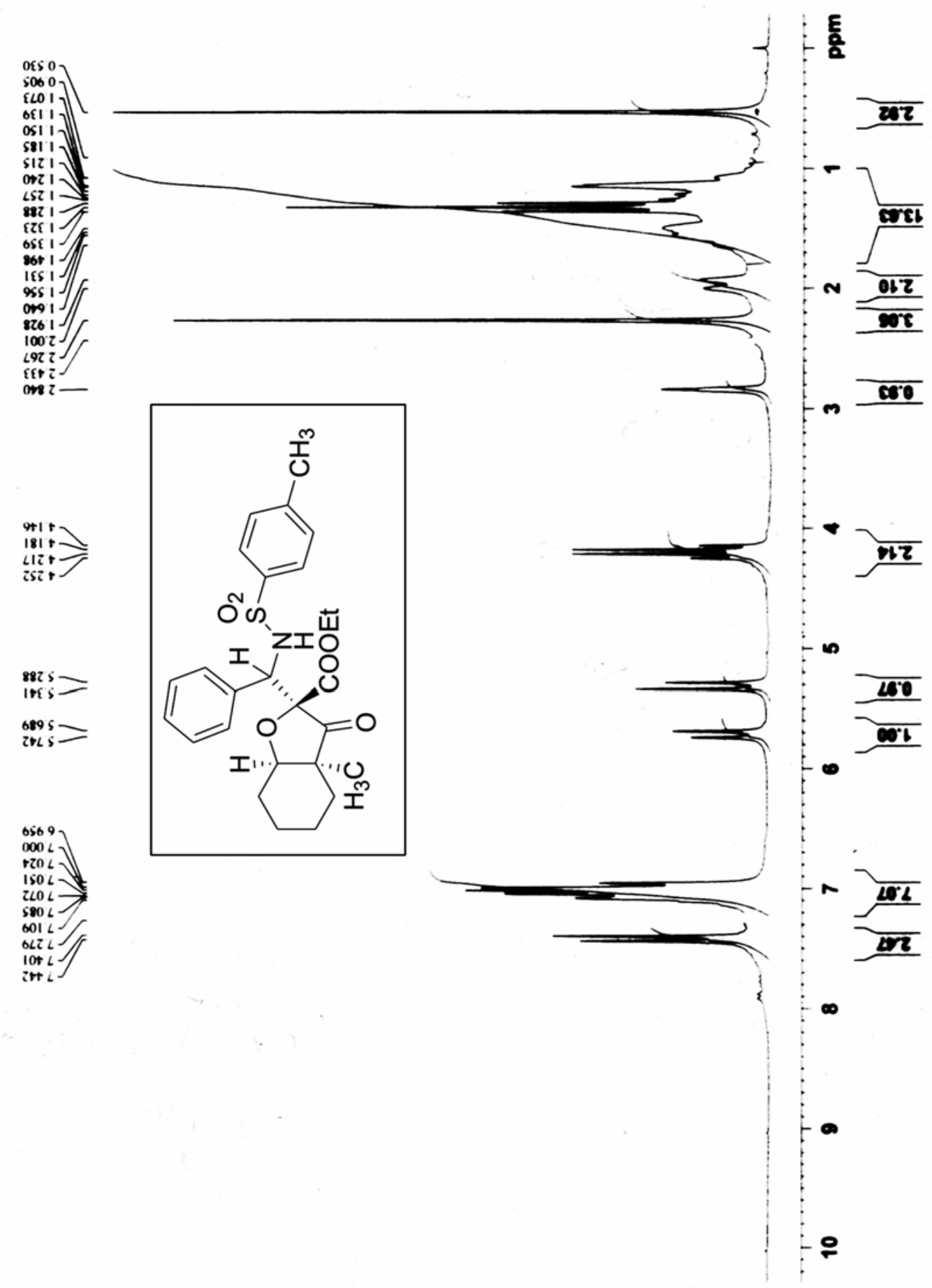



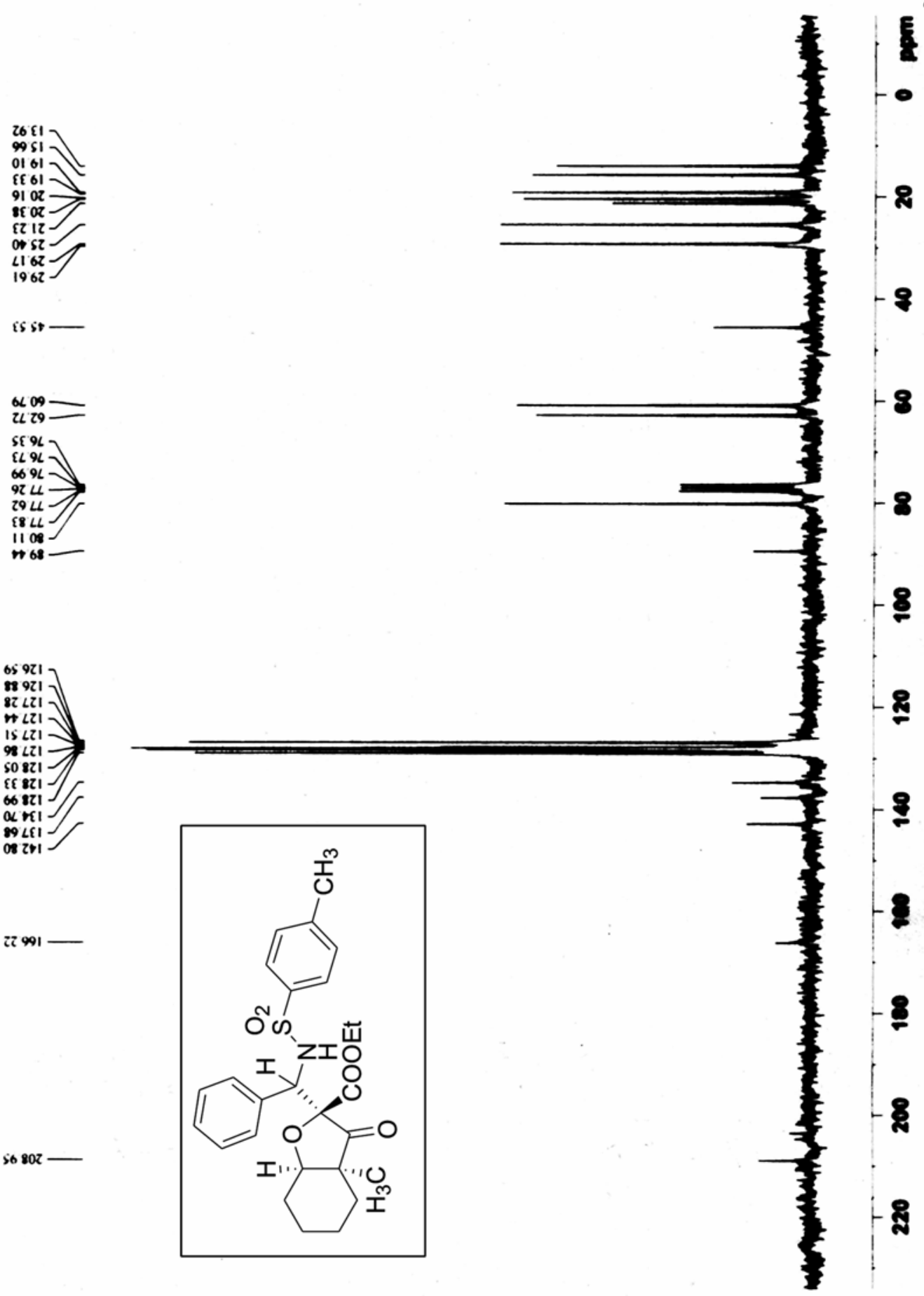

(5) 61

sc ox

ot 52

4162
1962

is st -

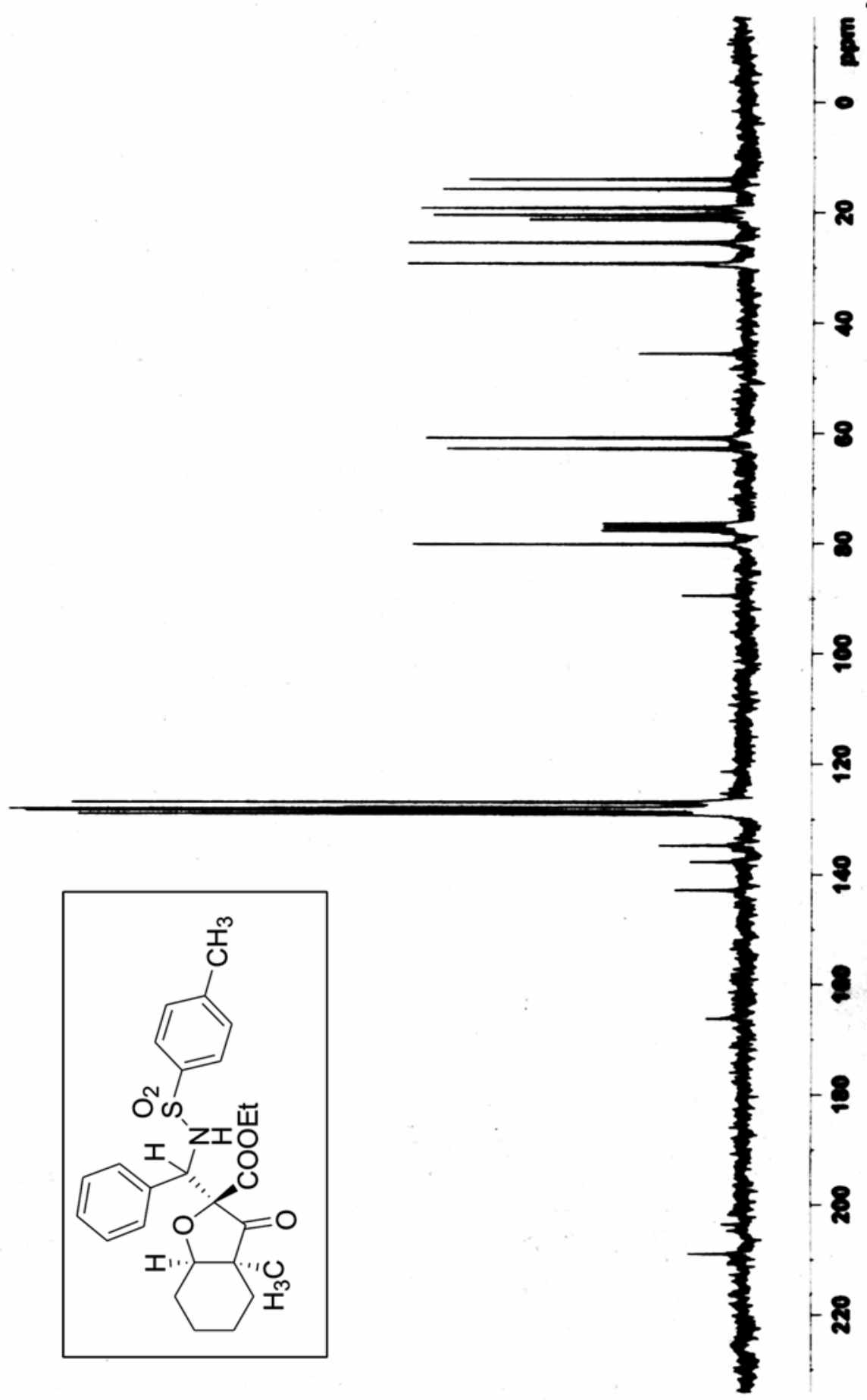

109

ธ๘ $\%$

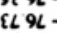

924

2914

$\rightarrow \infty$

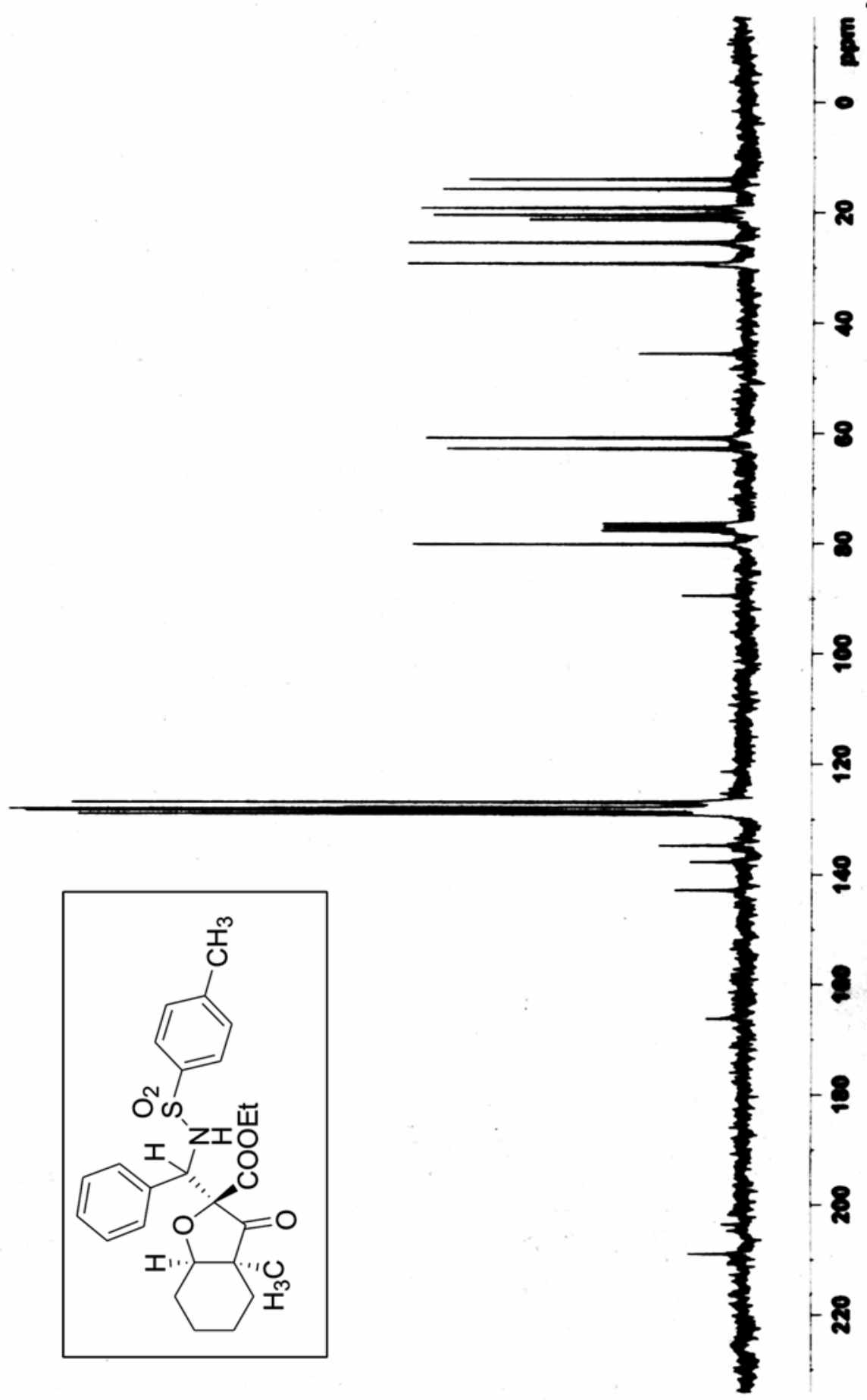

os 921

$889 z 1$
$8 z L Z 1$

8221
$u L 21$

Is LzI -

$98<z 1$

\&ธ

โะ 821
60821

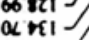

99 LEI

ob zt1

27991 


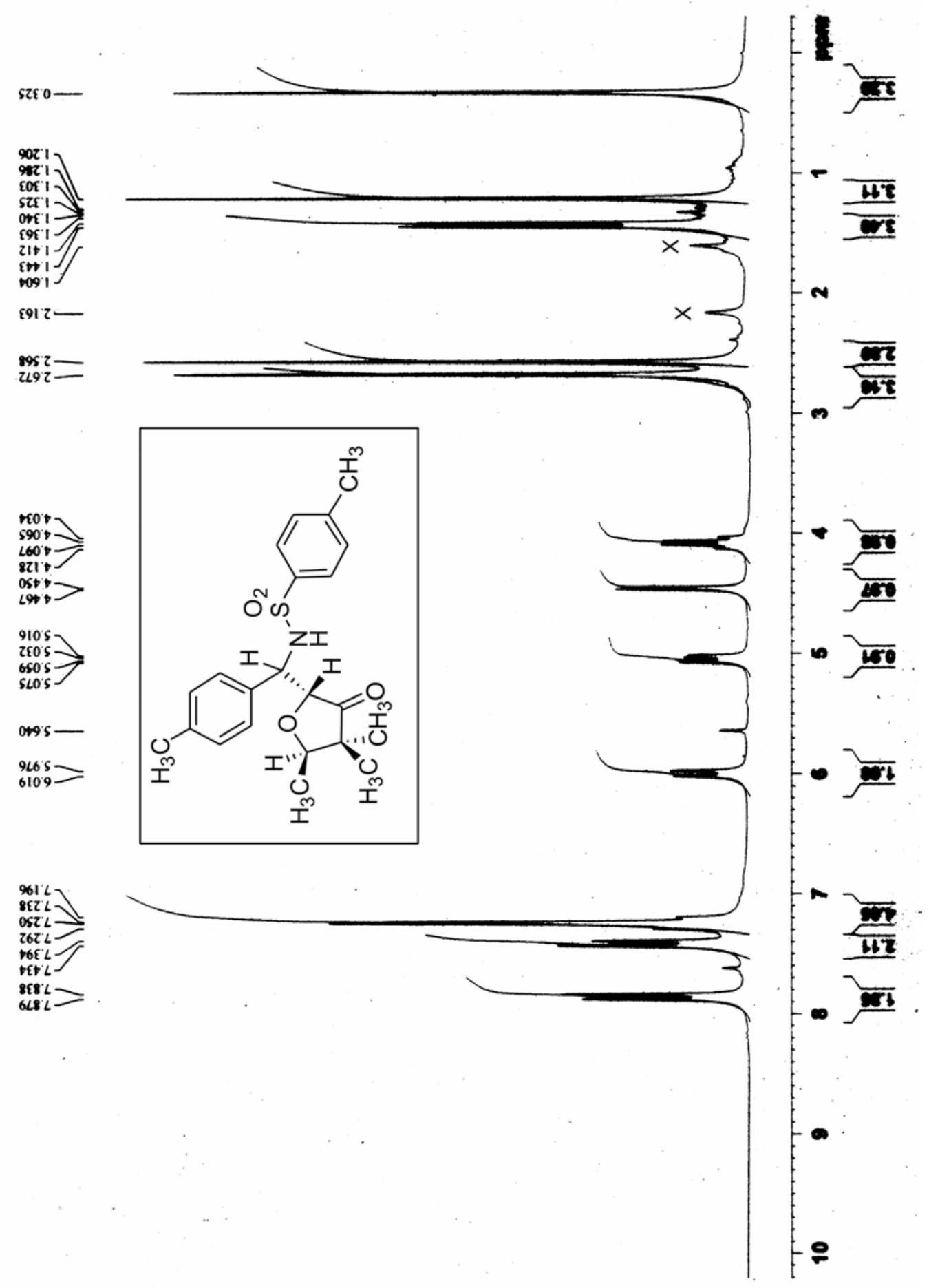




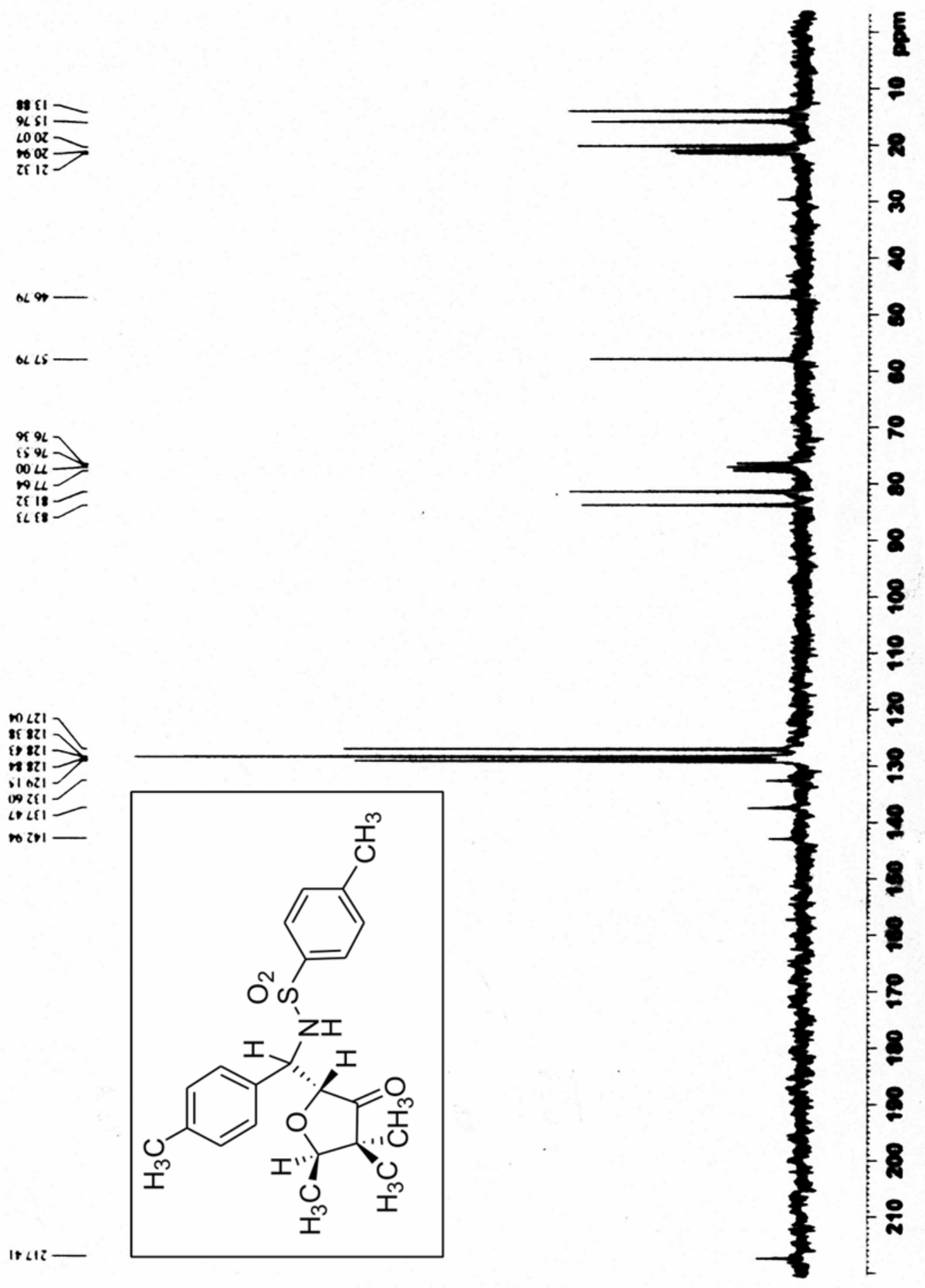




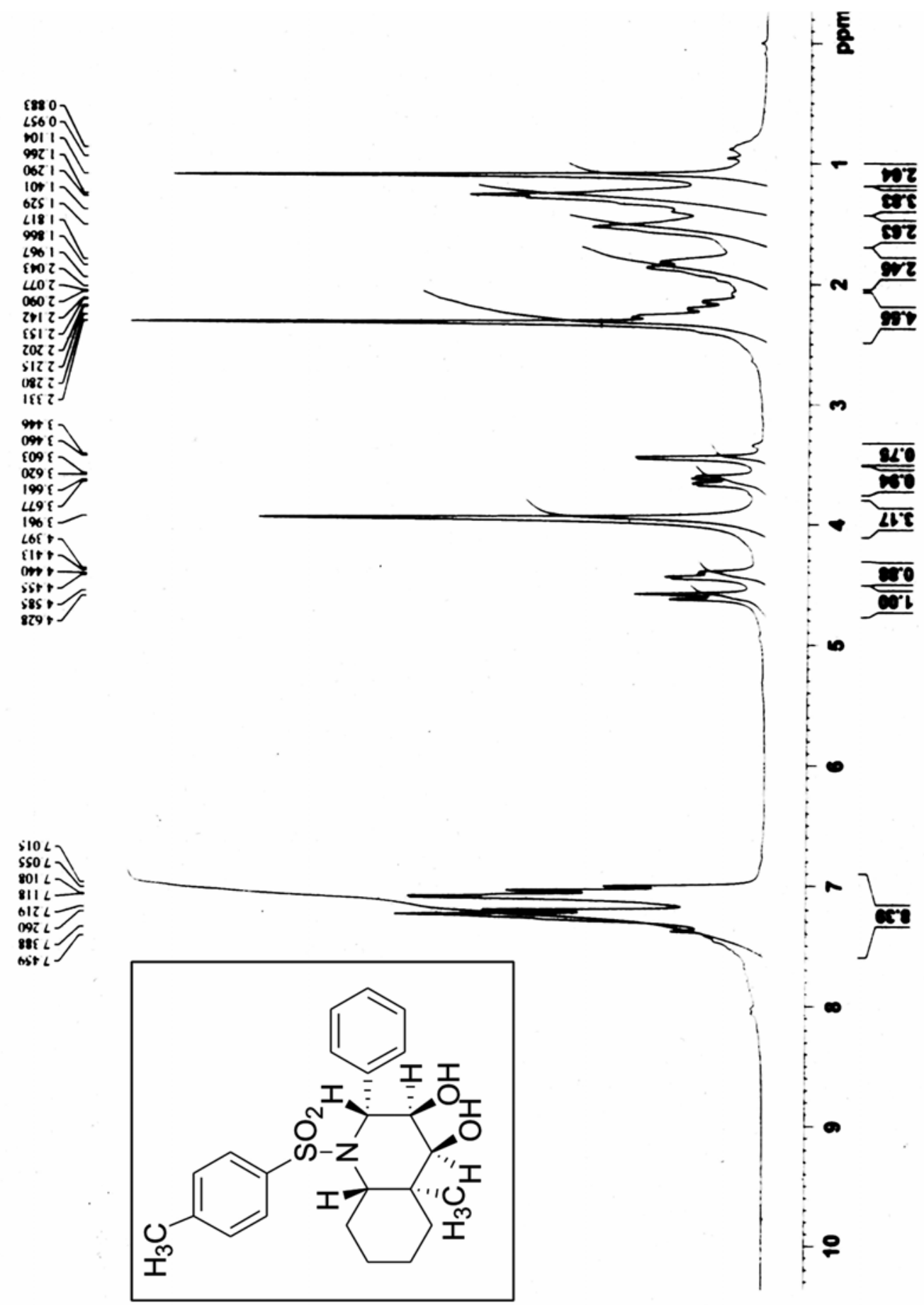



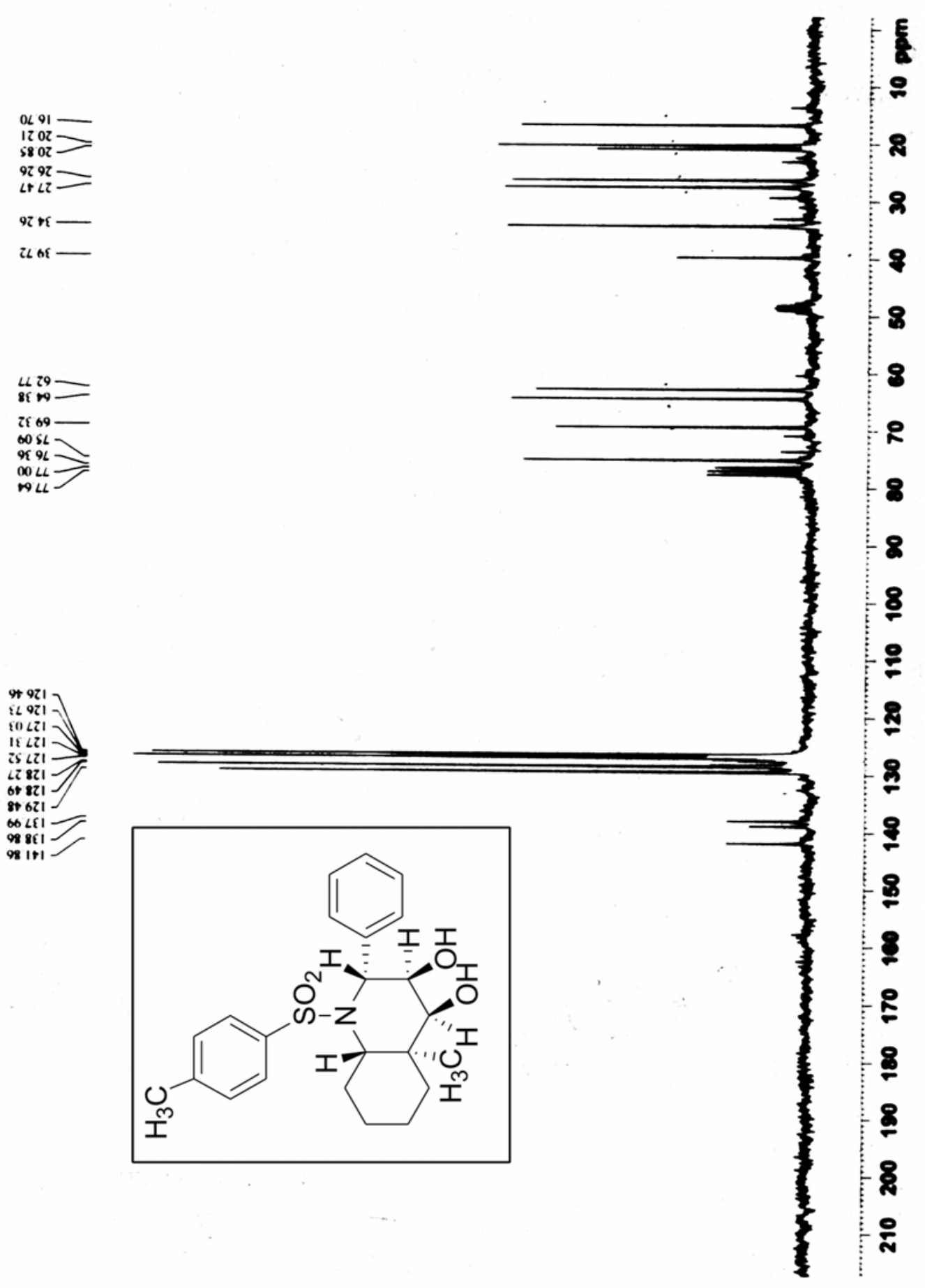


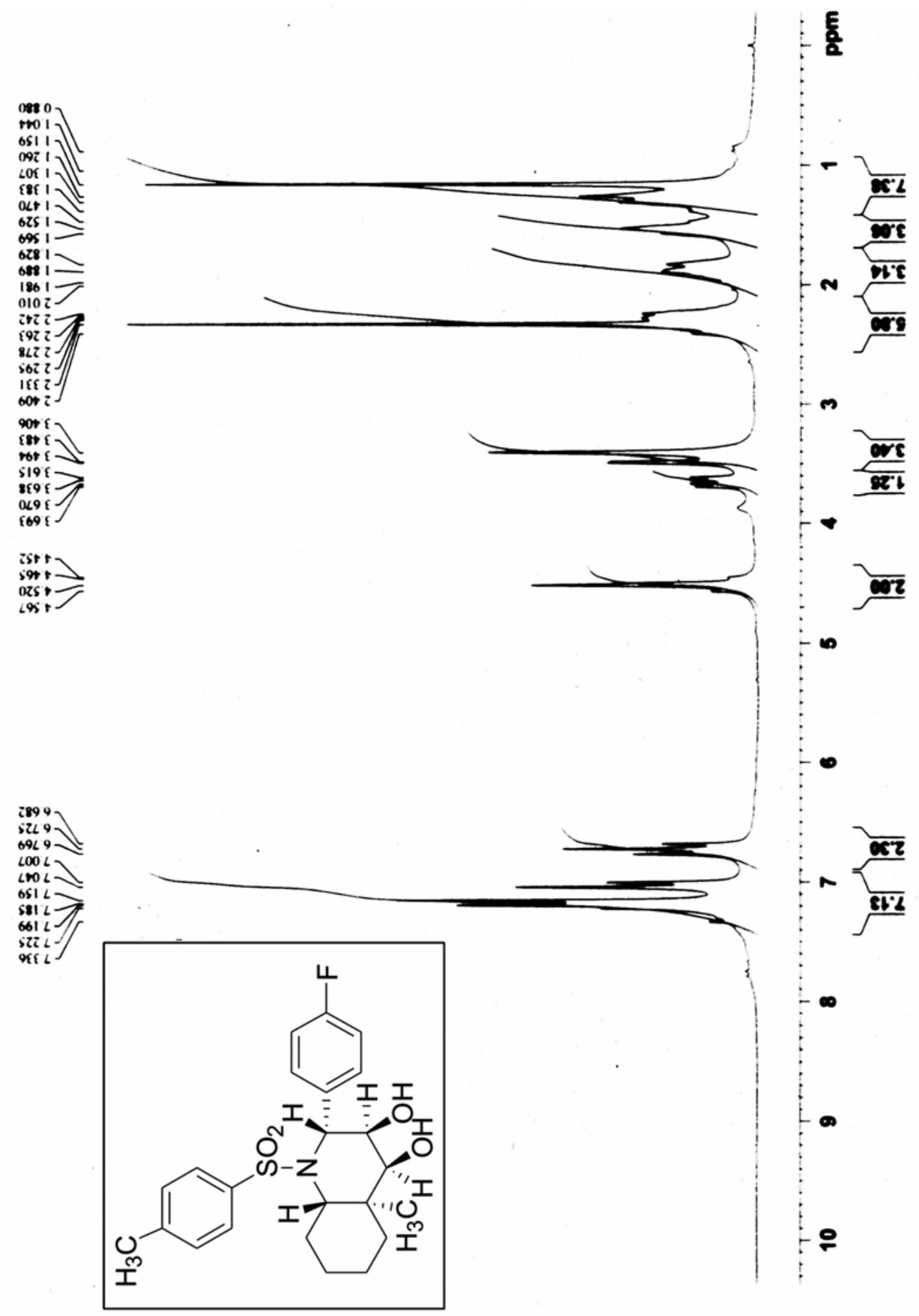



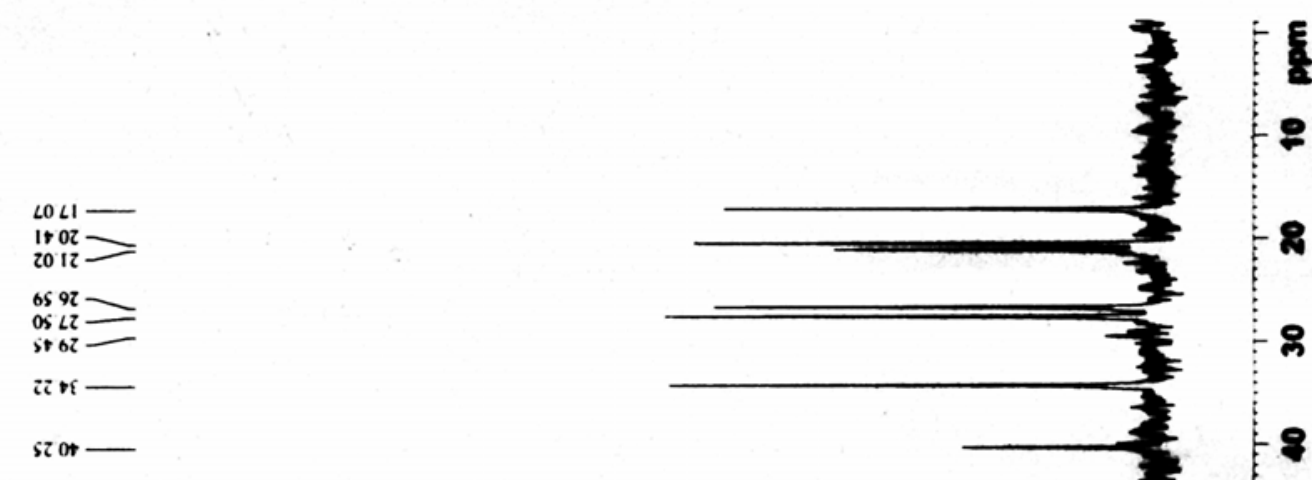

$1+02=$
2012

os 97
os 27

St 62

sz ot

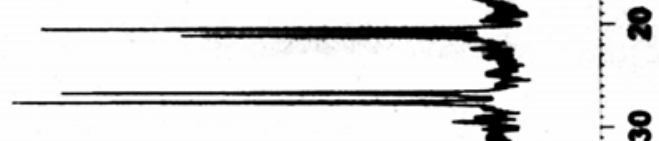

$88 \& 9$
6019
$1+79$
1589
0556
$189 L$
$\angle 69 L$
$19 L 6$
$586 L$

$19 L L$
$58 L L$

62651

81 म1 -
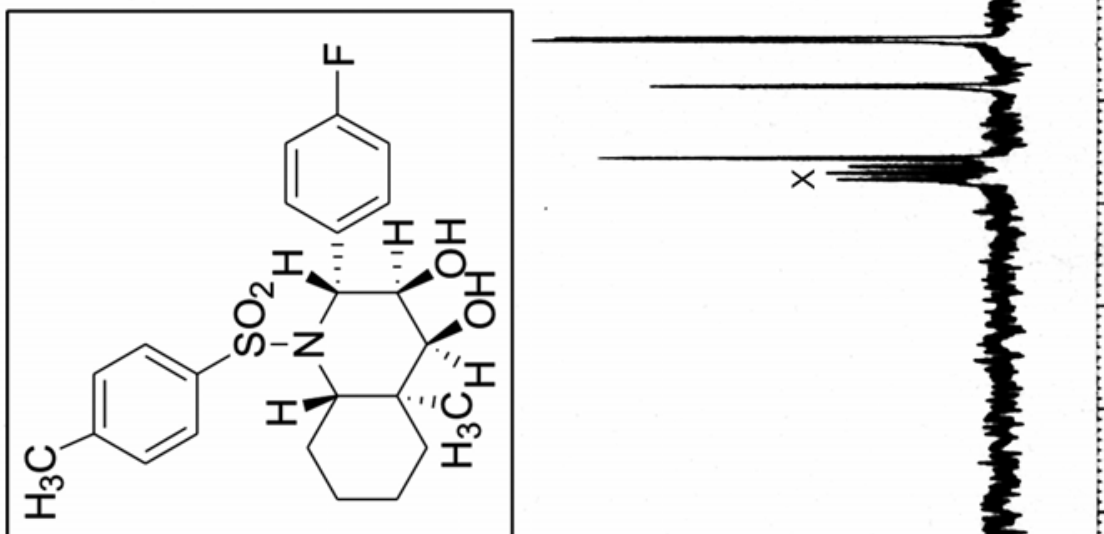

$R$

HSII -

$\infty 11=$
$2+11$

of 9 r

25821-

26151

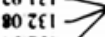

ก Z£।

25 6I -

(b) $1+1$

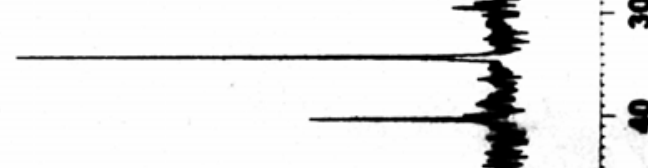

$-8$

$-8$

8

$-8$

$-8$

8

운

8

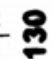

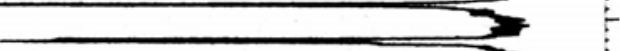

$-9$

8

8

온 


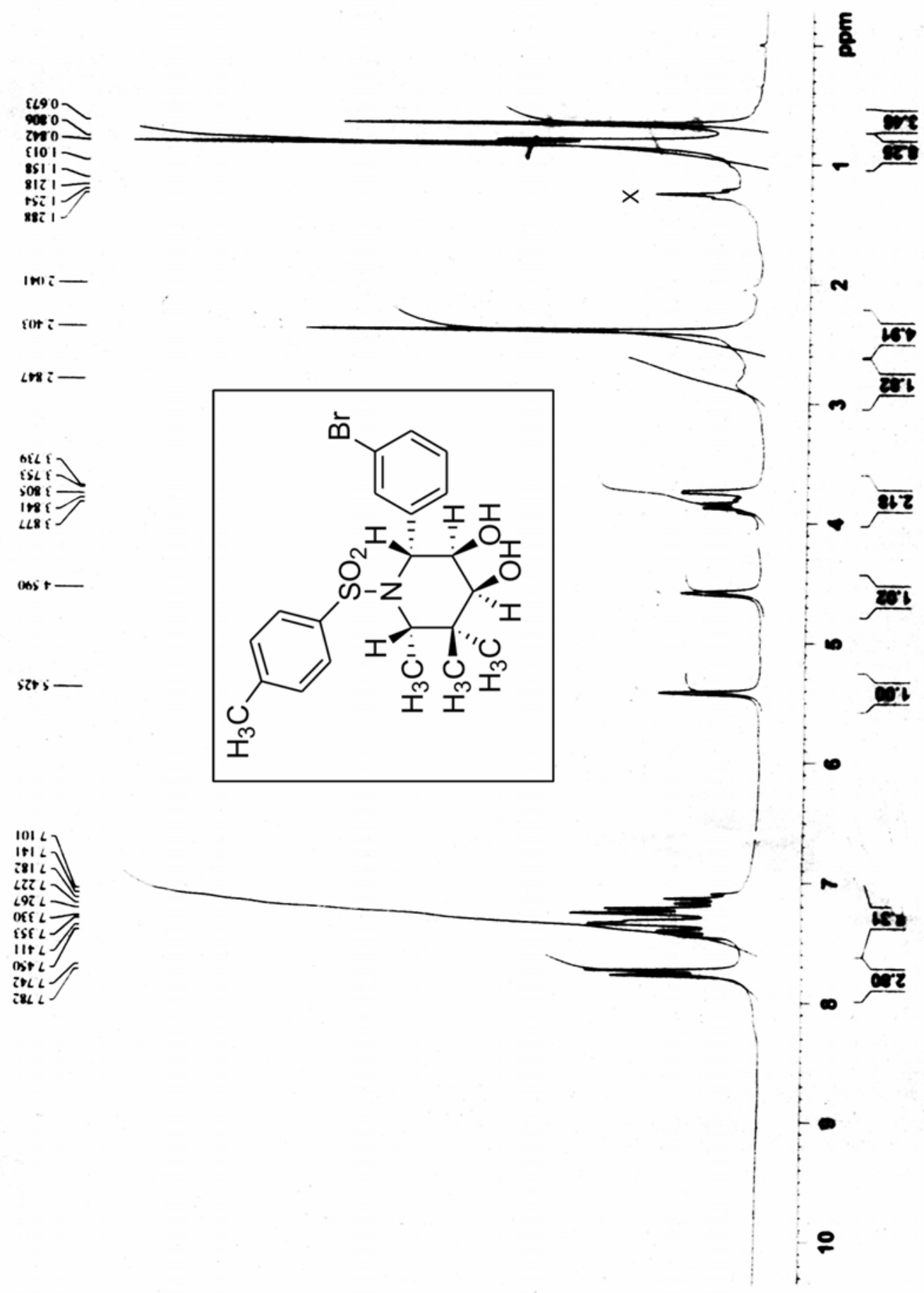



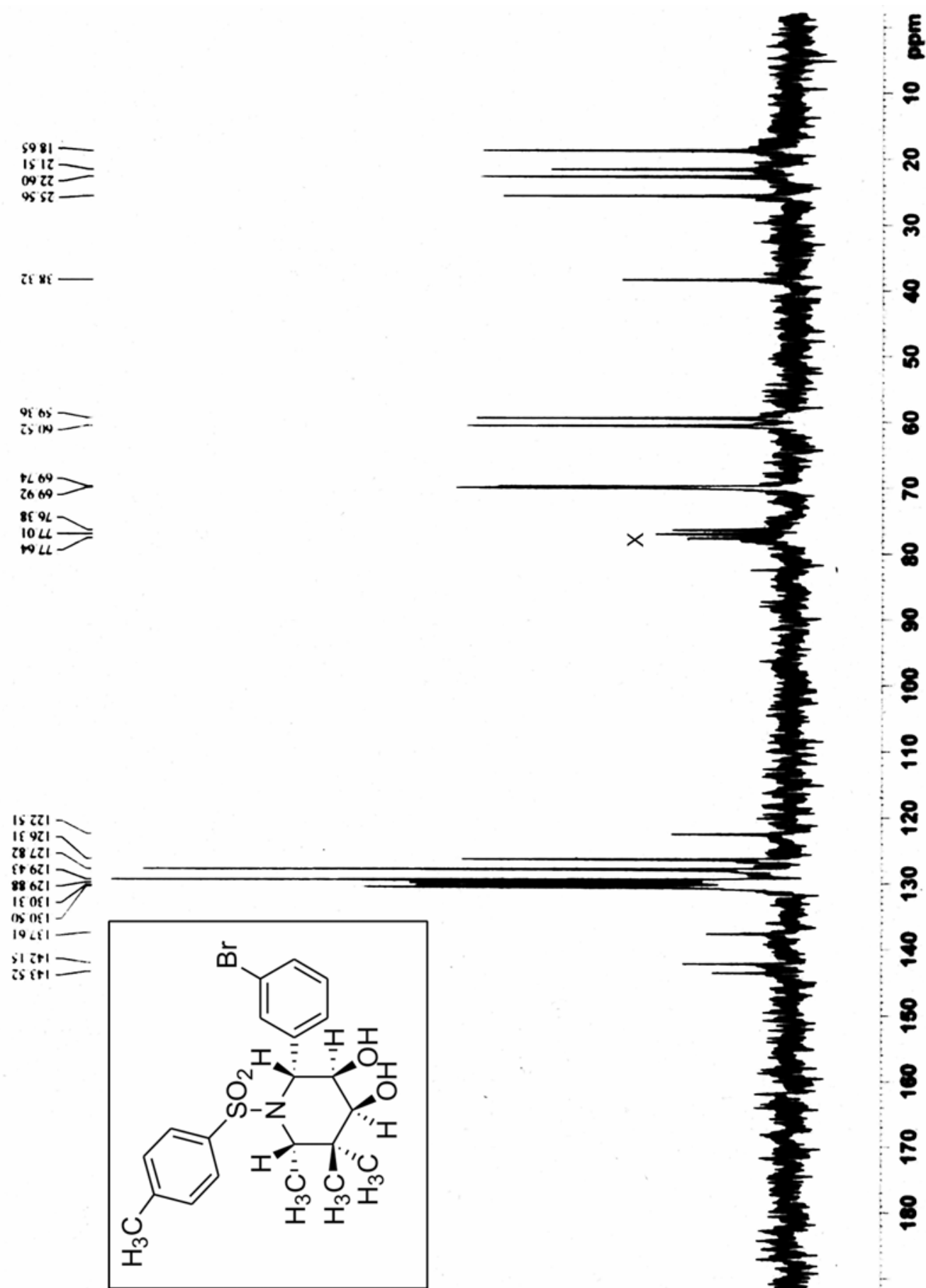

ำ

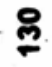

웅

8

8

운

Ф 


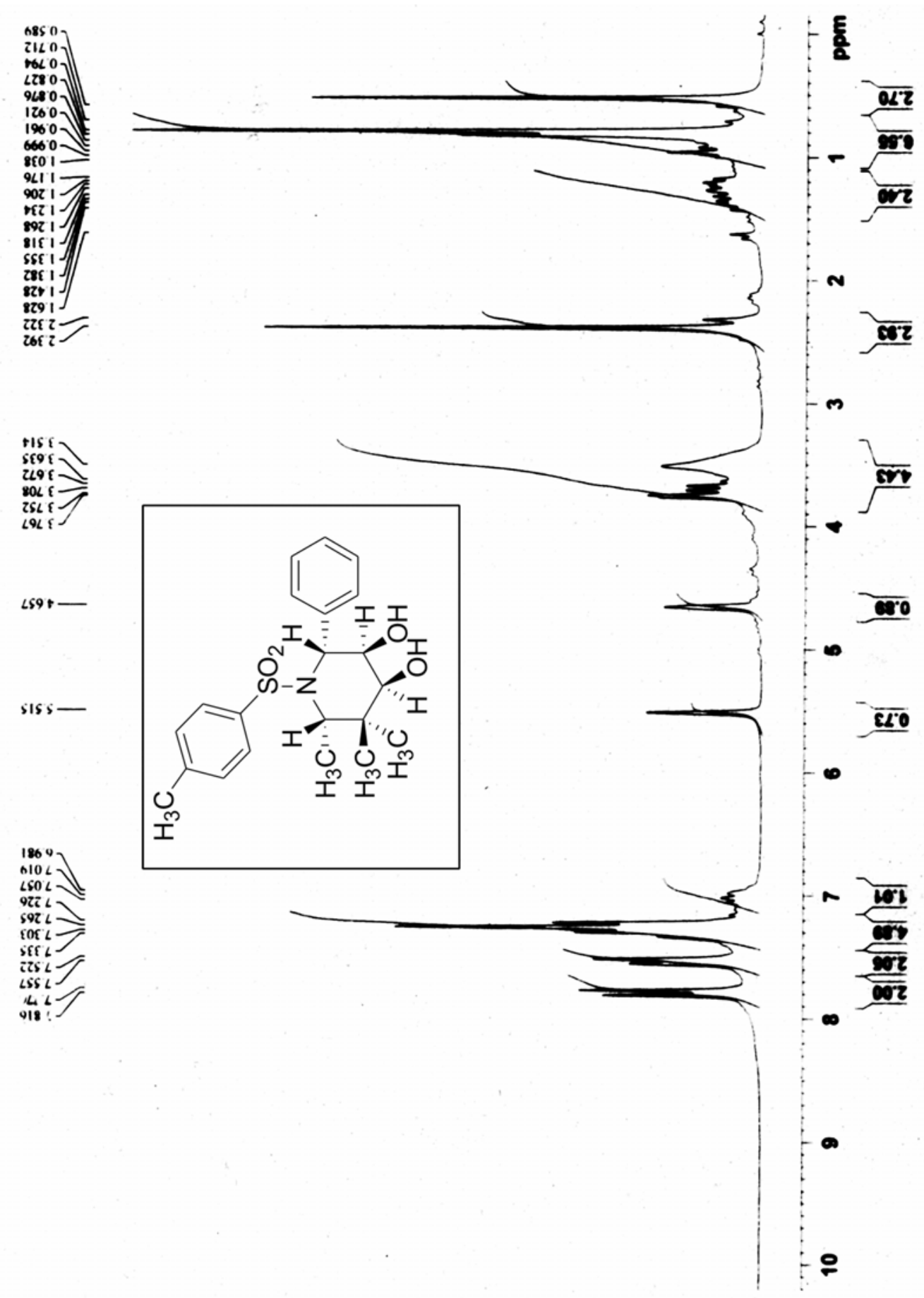




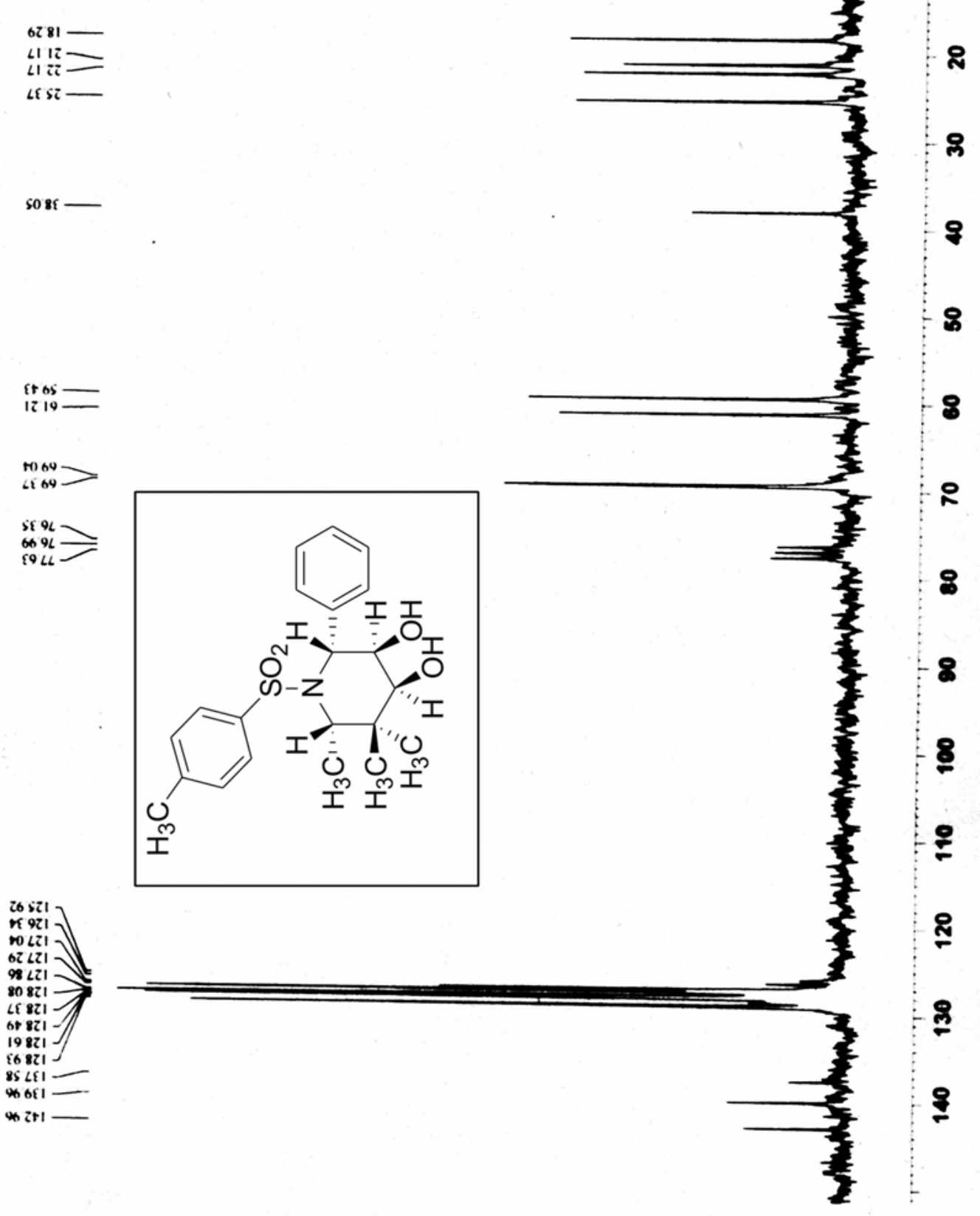




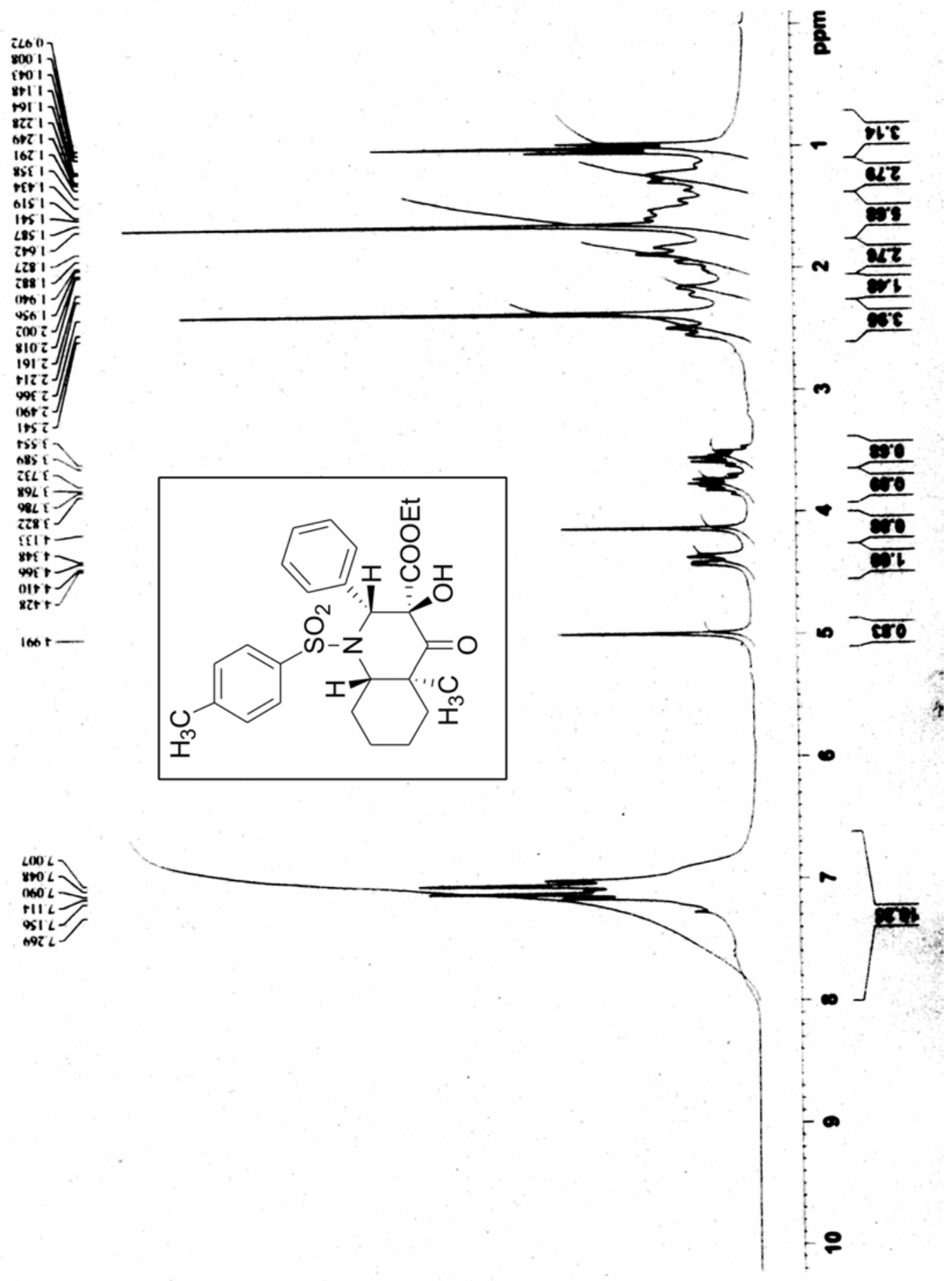



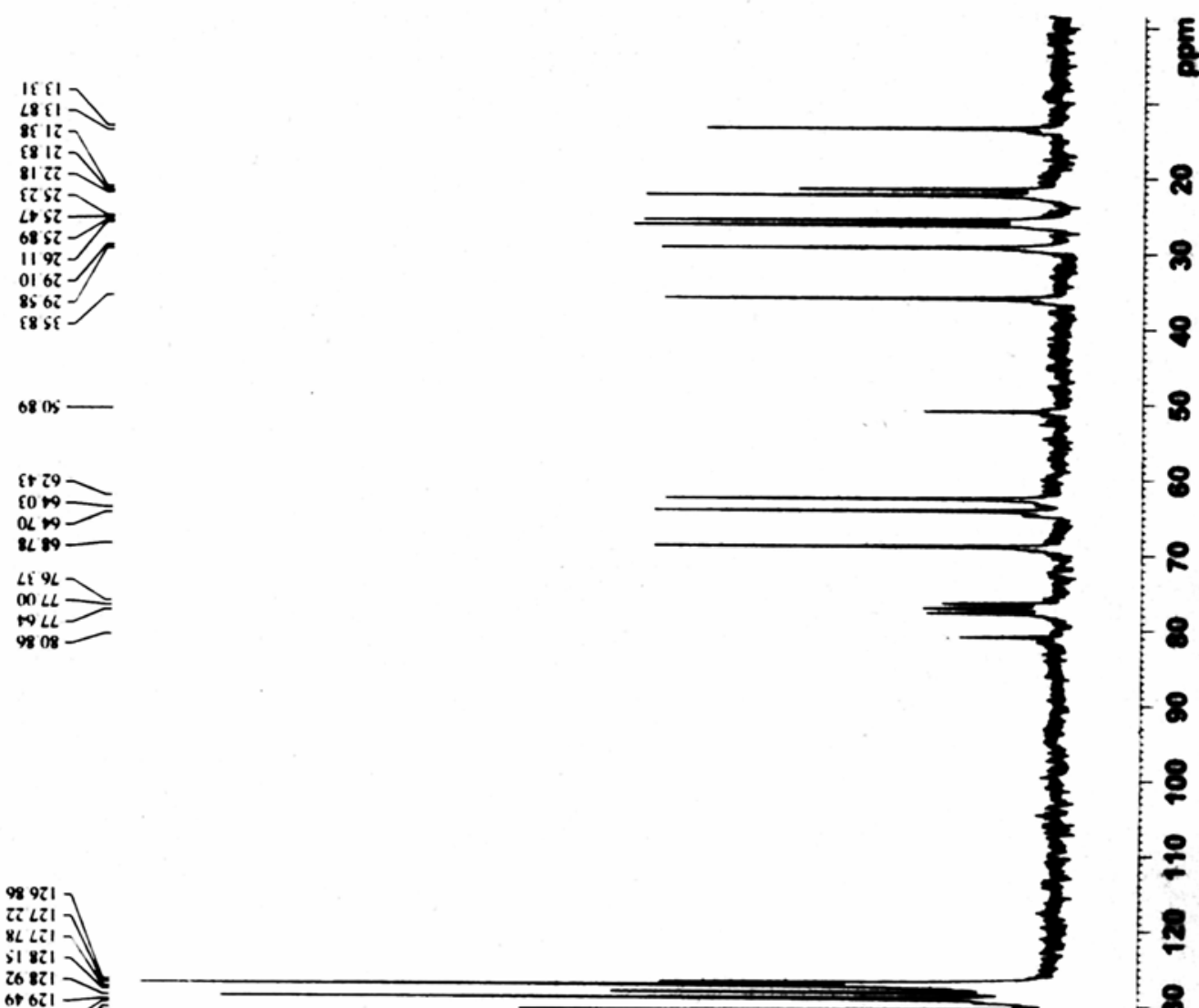

9921

$z i<z 1$

il 821

26211

98621

zs of 1

ร0 I โ1 -

6 โร1

92 6\{1

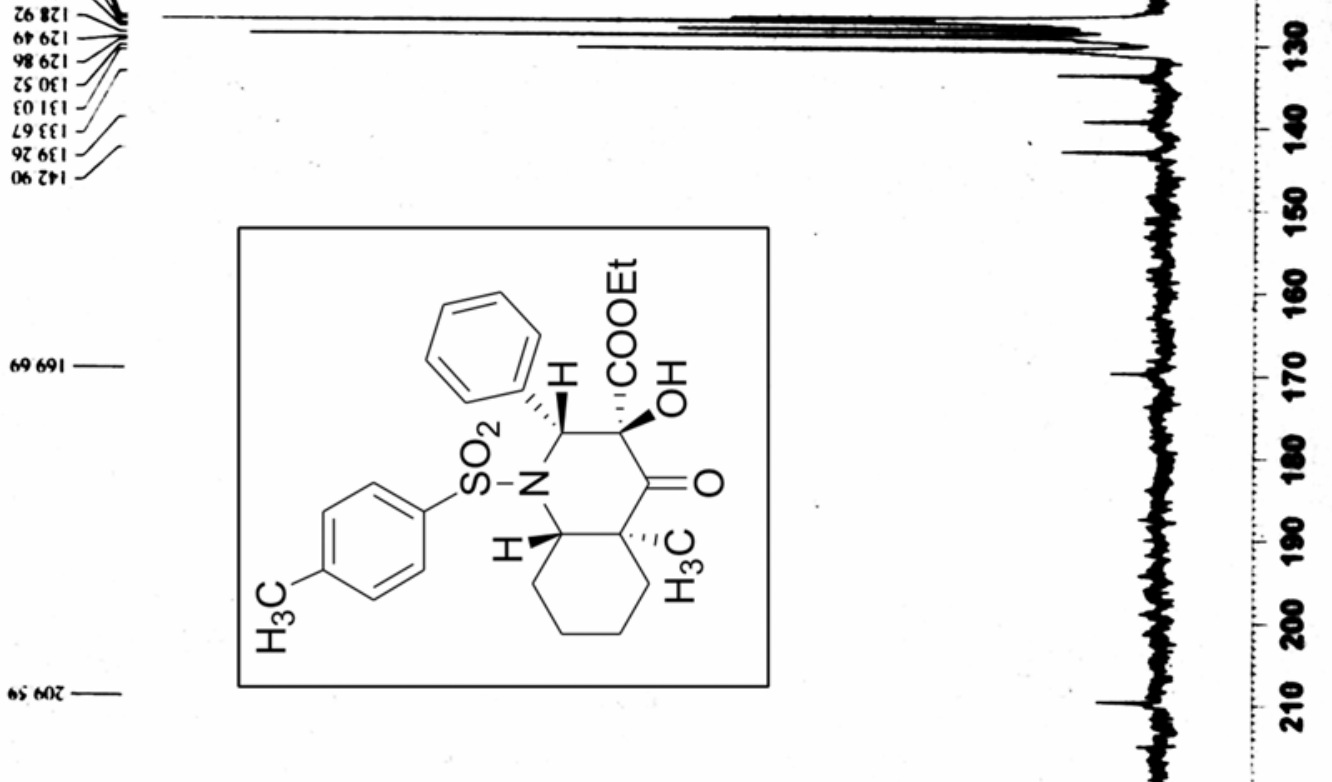

AS OOZ 


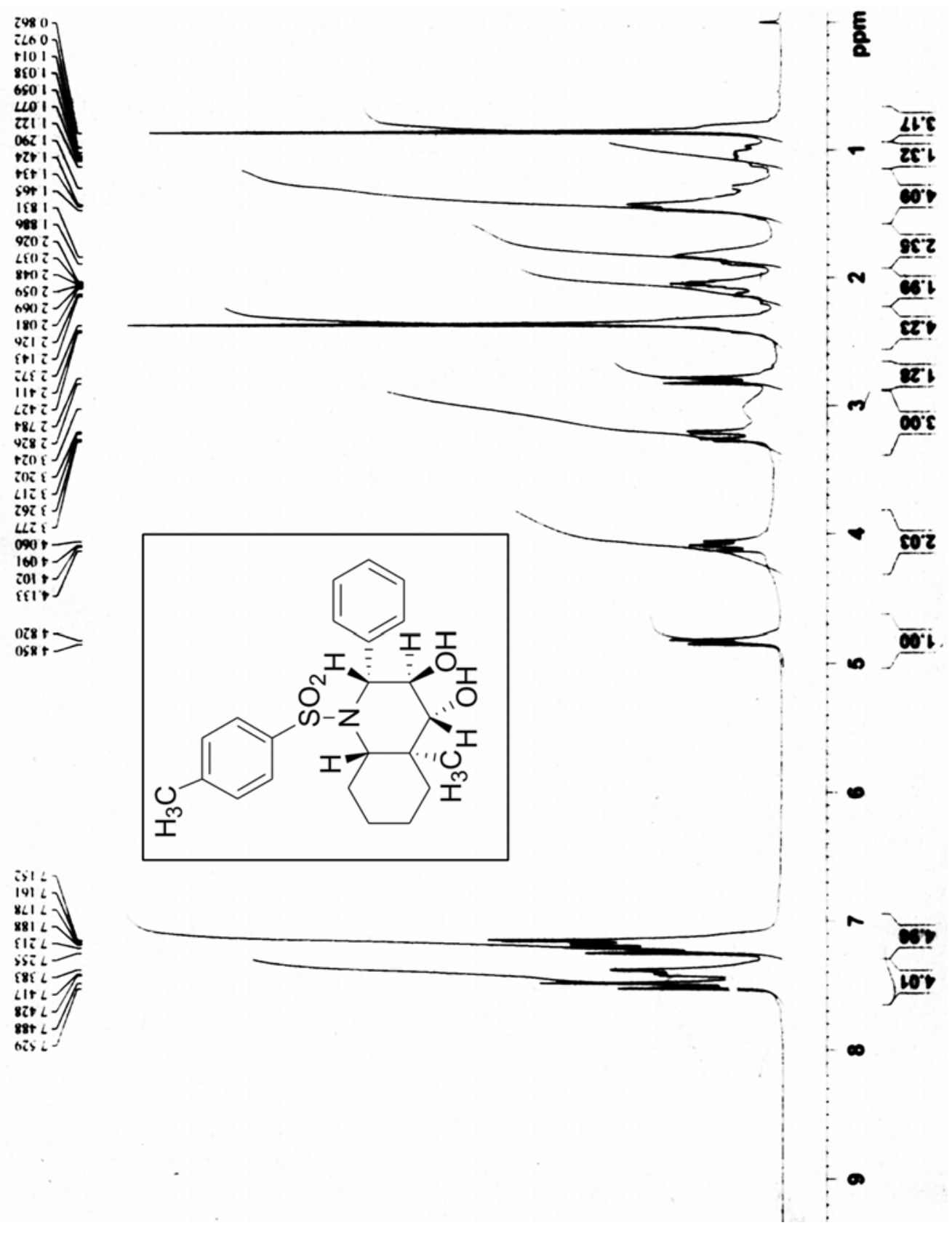




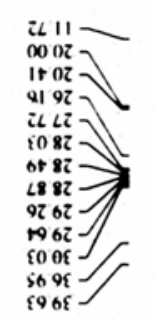

$00<9>$
$69<9>$
$8556-$
2018
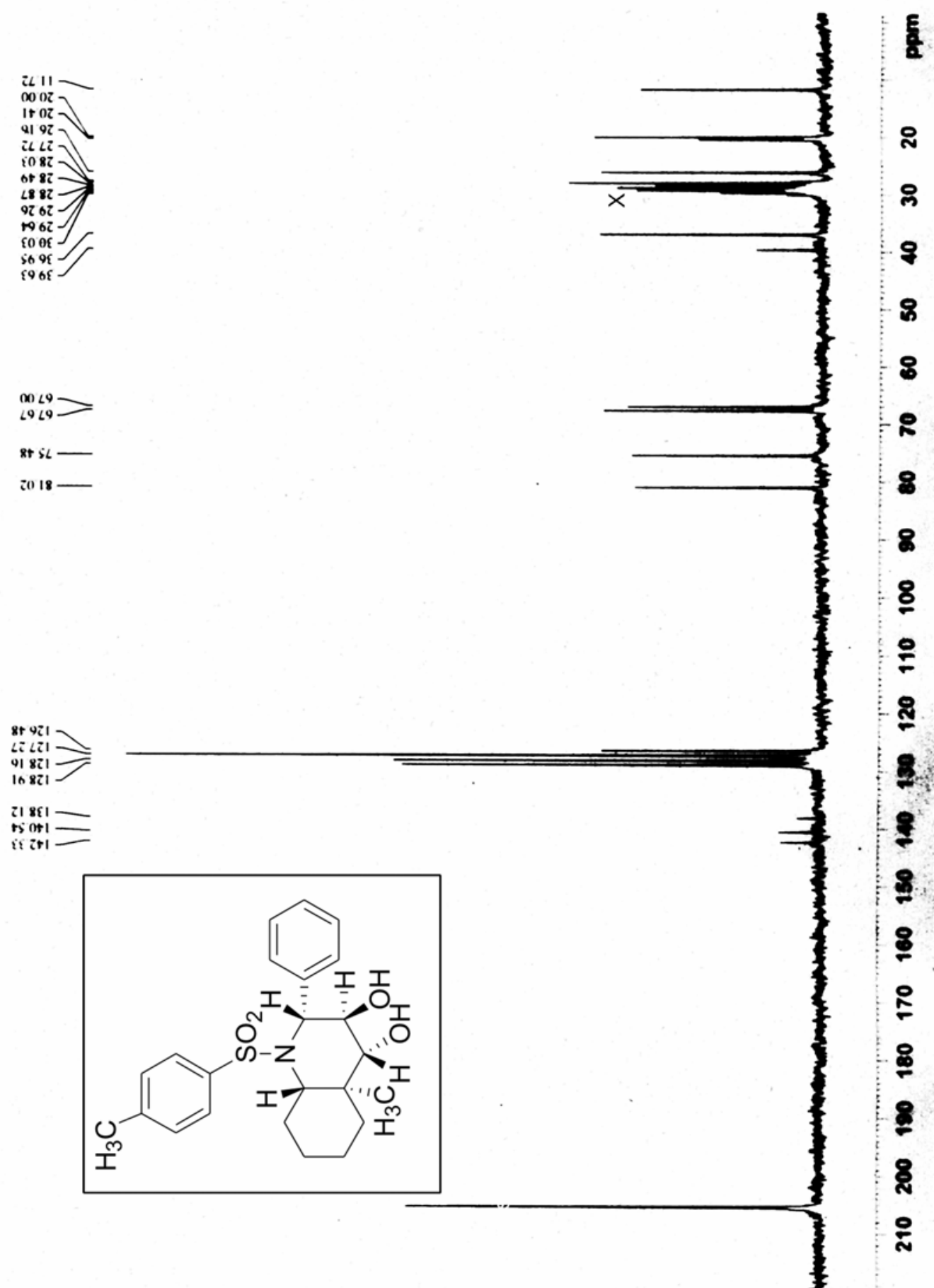


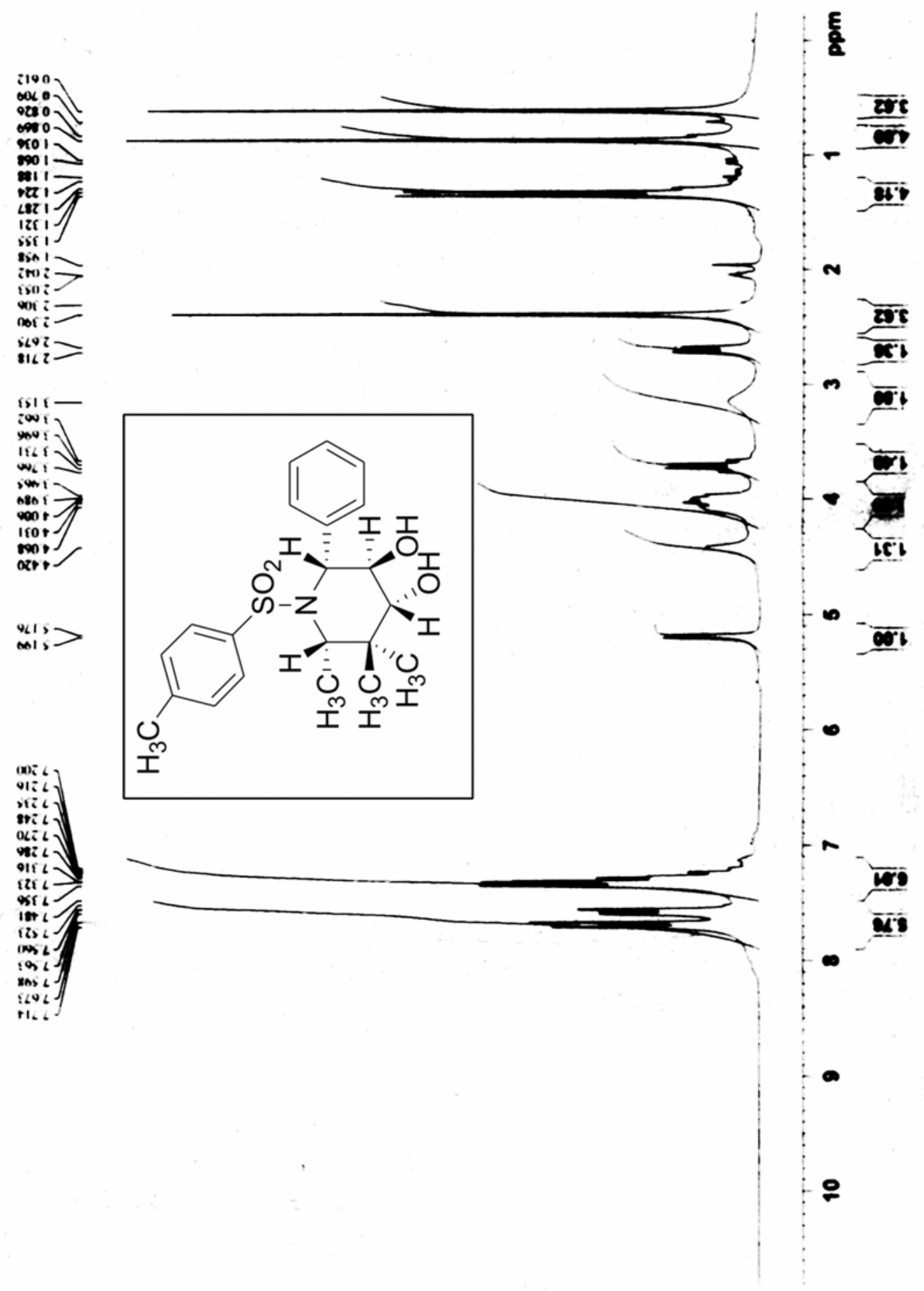




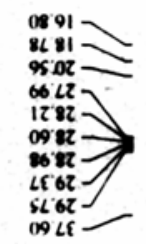

95 65 -

$i s \$ L=$
$S L 9 L=$

定

흠

8

\&

웅

8

8

2

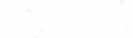

\$s 921

L4 $921-$

is 821

क6 821

$n z+1=$

$\underbrace{t z t+1}_{i \in t+1}=$

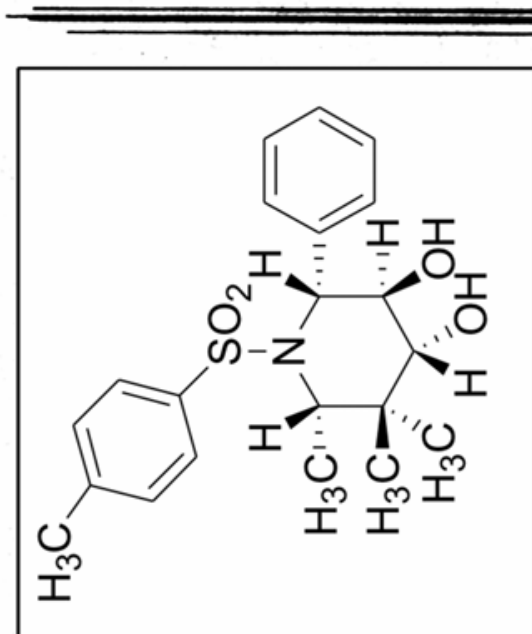

90502 